NBSIR 75-700

\title{
Results of Full-Scale Fire Tests With Photoelectric Smoke Detectors
}

Richard W. Bukowski and Richard G. Bright

Center for Fire Research

Institute for Applied Technology

National Bureau of Standards

Washington, D. C. 20234

September 1975

Final

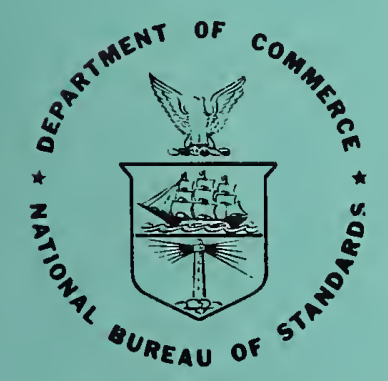

U.S. DEPARTMENT OF COMMERCE

QC NATIONAL BUREAU OF STANDARDS 

NBSIR 75-700

RESULTS OF FULL-SCALE FIRE TESTS

WITH PHOTOELECTRIC SMOKE DETECTORS

Richard W. Bukowski and Richard G. Bright

Center for Fire Research

Institute for Applied Technology

National Bureau of Standards

Washington, D. C. 20234

September 1975

Final

U.S. DEPARTMENT OF COMMERCE, Rogers C.B. Morton, Secretary James A. Baker, III, Under Secretary

Dr. Betsy Ancker-Johnson. Assistant Secretary for Science and Technology

NATIONAL BUREAU OF STANDARDS, Ernest Ambler, Acting Director 

LIST OF FIGURES. . . . . . . . . . . . . . . . . . . . . . iv

LIST OF TABLES . . . . . . . . . . . . . . . . . . . . v v

1. INTRODUCTION . . . . . . . . . . . . . . . . . . 1

2. EXPERIMENTAL PROCEDURES AND MATERIALS . . . . . . . . . . 3

2.1. Fire Test Room . . . . . . . . . . . . . . . . 3

2.2. Instrumentation ................. 4

2.2.1. Smoke Density Measuring Equipment . . . . . . 4

2.2.2. Temperature Recording ............ . 4

2:2.3. Carbon Monoxide .............. 4

2.2.4. Detector Actuation ............. . 4

2.3. Test Materials ................... 4

2.3.1. Shredded Paper ............... 5

2.3.2. Polystrene................. 5

2.3.3. Gasoline . . . . . . . . . . . . . 5

2.3.4. Wood Brand (UL Class A)............ 5

2.3.5. Cotton . . . . . . . . . . . . . 5

2.3.6. Polyurethane ................ 6

2.4. Smoke Detectors . . . . . . . . . . . . 6

2.5. Test Procedures . . . . . . . . . . . . . 6

3. RESULTS . . . . . . . . . . . . . . . . 8

4. DISCUSSION : • : : . • . . . . . . . . . . . . . . 8

4.1. Test Series No. 1 - Shredded Paper . . . . . . . . 8

4.2. Test Series No. 2 - Polystyrene ......... . . . 12

4.3. Test Series No. 3 - Gasoline - $100 \mathrm{cc}$. . . . . . . 12

4.4. Test Series No. 4 - Gasoline - $200 \mathrm{cc}$. . . . . . . 12

4.5. Test Series No. 5 - One Wood Brand . . . . . . . . 13

4.6. Test Series No. 6 - Two Wood Brands . . . . . . . . 13

4.7. Test Series No. 7 - Two Wood Brands ......... . 13

4.8. Test Series No. 8 - One Wood Brand ......... . 13

4.9. Test Serles No. 9 - Wood Brand on Hot Plate . . . . . 14

4.10. Test Series No. 10 - Polyurethane - Two Pieces . . . . . 14

4.11. Test Series No. 11 - Polyurethane - Three Pieces . . . . 14

4.12. Test Series No. 12 - Polyurethane - One Plece . . . . 15

4.13. Test Series No. 13 - Smoldering Cotton . . . . . . . 15

4.14. Carbon Monoxide .. . . . . . . . . . . . 16

4.15. Average Air Velocities . . . . . . . . . . . 17

4.16. Temperatures . . . . . . . . . . . . . . 17

4.17. Photoelectric Smoke Detector "J" . . . . . . . . 18

5. SUMMARY AND CONCLUSIONS . . . . . . . . . . . . . . 18

6. ACKNOWLEDGEMENTS • . . . . . . . . . . . . . . . . . 22

7. REFERENCES • . . . . . . . . . . . . . . . . . 22 


\section{LIST OF FIGURES}

Page

Figure 1. Fire test room floor plan. . . . . . . . . . . . 24

Figure 1a. Results of fire test No. 1. . . . . . . . . 25

Figure 2. Results of fire test No. 2. . . . . . . . . 26

Figure 3. Results of fire test No. 3 . . . . . . . . . 27

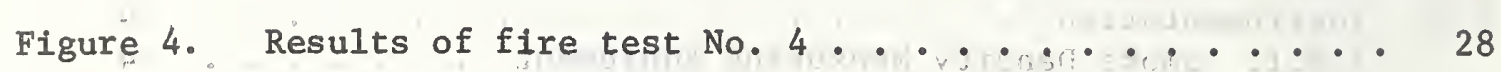

Figure 5. Results of fire test No. 5 . . . . . . . . . 29

Figure 6. Results of fire test No.6............ 30

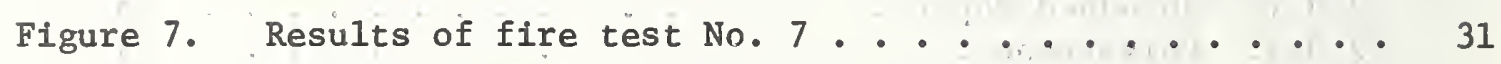

Figure 8. Results of fire test No. 8................. 32

Figure 9. Results of fire test No. 9. . . . . . . 33

Figure 10. Results of fire test No. 10............ 34

Figure 11. Results of fire test No. 11. . . . . . . . . . . 35

Figure 12. Results of fire test No. 12. . . . . . . . . . 36

Figure 13. Results of fire test No. 13, . . . . . . . . 37

Figure 14. Results of fire test No. 14.

Figure 15. Results of fire test No. 15. . . . . . . . 39

Figure 16. Results of fire test No. 16. . . . . . . . . 40

Figure 17. Results of fire test No. 17a . . . . . . . . 41

Figure 18. Results of fire test No. 19. . . . . . . . . . . . 42

Figure 19. Results of fire test No. 20............ . . 43

Figure 20. Results of fire test No. 21. . . . . . . . . . 44

Figure 21. Results of fire test No. 22. . . . . . . . . . 45

Figure 22. Results of fire test No. 23. . . . . . . . . . . 46

Figure 23. Results of fire test No. 24. . . . . . . . . . 47 


\section{LIST OF FIGURES, cont'd}

Page

Figure 24. Results of fire test No. 25. . . . . . . 48

Figure 25. Results of fire test No. 26. . . . . . . 49

Figure 26. Results of fire test No. 27. . . . . . . 50

\section{LIST OF TABLES}

Table 1. List of Smoke Detectors. . . . . . . . . 7

Table 2. Description of Test Fires. . . . . . . . . 9

Table 3. Detector Alarm Response - In Seconds ......... 10

Table 4. Detector Alarm Response - In Seconds Arranged by

Test Series............... . 11 
RESULTS OF FULL-SCALE TESTS WITH PHOTOELECTRIC SMOKE DETECTORS

Richard W. Bukowski ${ }^{1}$

and

Richard G. Bright

In February 1974, a series of ful1-scale fire tests were conducted to determine whether photoelectric-type smoke detectors could respond to the same types of fires used to assess the performance of ionization-type smoke detectors. The types of fires employed in the tests are the same as those outlined In Underwriters' Laboratorles, Inc., Standard No. 167. In addition to the UL-167 test fires, fires involving polyurethane (flaming mode) and cotton (smoldering mode) were added to the test serles. One detector, ut1lizing a Taguch gas sensor (TGS), was included in the test series for evaluation purposes. The test results indicated that the better photoelectric smoke detectors, i.e., those having little obstruction to slow-moving smoke can, in general, detect the same test fires as the ionization chamber smoke detectors in approximately the same time scale. For the smoldering cotton fire, the photoelectric detectors were significantly faster than the ionization chamber detectors. The TGS fire detector was unable to detect most of the test fires but the standard fires are not that standard or specific and hence present a significant ambiguity.

Key words: Fire detectors; ionization chamber smoke detectors; photoelectric smoke detectors; smoke detectors; Taguchi gas sensors.

\section{INTRODUCTION}

There are two different types of conventional smoke detectors sold in the U.S. The difference between the detectors is in the method used to sense the presence of smoke. The one smoke detector, generally referred to as a photoelectric detector, light scattered from smoke particles that have entered the sensing chamber of the detector is used to actuate an alarm. In the other smoke detector, generally referred to as an ionization chamber detector, a radioactive source material ionizes the air within the sensing chamber, producing a minute current flow. When smoke particles enter this sensing chamber, the particles cause a reduction in this current flow which is used to actuate an alarm. For a more detailed description of conventional smoke detectors as well as other fire detectors see $[1]^{2}$.

$I_{\text {At }}$ the time this paper was written the author was a Research Associate for Underwriters' Laboratories at the National Bureau of Standards.

Mr. Bukowski has returned to UL.

${ }^{2}$ Numbers in brackets correspond with the literature references listed at the end of this paper. 
The major testing and approvals laboratory for smoke detectors in the U.S. is the Underwriters' Laboratories (UL) of Northbrook, Illinois. At present, UL is testing conventional smoke detectors to two different standards. Photoelectric smoke detectors are tested to the requirements of UL-168 [2] while ionization chamber smoke detectors are tested to UL-167.[3]. In addition, if nonconventional smoke detectors, i.e., detectors using combustion aerosol sensors other than photoelectric or ionization chamber sensors, are submitted to UL for examination, these nonconventional smoke detectors are subjected to the requirements of UL-167 as opposed to UL-168.

These two standards are almost identical except for one significant difference. This difference is the requirement in UL-167 that the smoke detector perform satisfactorily in sensing four, full-scale fire tests. UL-168 omits the full-scale fire tests, a requirement that makes UL-167 the more demanding of the two standards. UL-167 requires that at least two of four detectors subjected to each of four standard fires shall alarm within two minutes for the shredded paper, the polystyrene and the gasoline test fires. Alarm within four minutes is required for the wood brand test fires.

This difference between the two standards has been the subject of some controversy. The controversy becomes particularly strident when the developer of a new combustion aerosol sensor approaches UL for an examination of his detector and discovers his detector must pass the requirements of UL-167 as opposed to UL-168.

It has been argued that there should be only one standard for testing and approval of smoke detectors regardless of the sensing method used. It is difficult to quarrel with this thesis, particularly if one considers that the smoke detectors' end use is the same; that is, the detection of fires. As UL-167 is the more rigorous of the two standards, primarily because of the inclusion of full-scale test fires, UL-167 is considered to be the most appropriate to use as a.basis for a single standard.

Photoelectric smoke detectors have, however, been tested and approved under UL Standard 168 for several years. The question that arises is how well would the photoelectric smoke detectors perform if subjected to the same full-scale fire tests as are the ionization chamber smoke detectors?

It was an attempt to answer this question which stimulated the series of tests reported herein. NBS, in cooperation with UL, conducted a series of 26 fire tests at the UL facilities in Northbrook, Illinois, during the period of February 11-15, 1974. The same test facilities and the same test fires as described in UL-167 were utilized. In addition to the four standard test fires of UL-167, a smoldering cotton fire and several flaming polyurethane flexible foam fires were added to the test series. The purpose in adding the smoldering cotton fire to the test series was to compare the performance of photoelectric detectors against ionization chamber detectors to a non-flaming cellulosic fire. Polyurethane is used as a fire test material in Europe for assessing the performance of smoke detectors. 
Eight different photoelectric smoke detectors were chosen for the test series. Seven of these detectors were chosen because of their good response to slow-moving smoke as determined by laboratory analysis at NBS. It was thought this would be the key as to whether or not these photoelectric smoke detectors would perform satisfactorily. The eighth photoelectric smoke detector chosen was one noted for having response problems to slow-moving smoke. Laboratory experience indicated that this detector would experience difficulty in detecting the test fires. To give the detector every chance its sensitivity was set as high as possible without provoking false alarms.

For correlation and comparison purposes, two ionization chamber smoke detectors were included in the test series. One was a singlestation model of the type sold for residential protection. The other was a unit-type or commercial detector used in automatic fire detection systems of the type installed in warehouses, nursing homes, and computer spaces.

Several U.S. detector manufacturers are selling smoke/fire detectors, using the Taguchi gas sensor (TGS). The TGS sensor is manufactured by Figaro Engineering of Osaka, Japan.

The TGS sensor is a sintered $\mathrm{N}$-type semiconductor bulk device mainly composed of tin dioxide $\left(\mathrm{SnO}_{2}\right)$ whose conductivity increases in the presence of combustible gases such as carbon monoxide, methane, propane and, to a lesser extent, the unburnt hydrocarbons present in some fires. When used with a simple amplifier, carbon monoxide on the order of 300 to 1,000 parts per million can be detected. In addition, if several combustible gases are present in the atmosphere, such as carbon monoxide and unburnt hydrocarbons, the TGS sensor will respond to the cumulative effect of these gases. For additional information on TGS sensors as smoke and fire detectors see reference [4]. One detector, employing the TGS and sold as a single-station, home smoke/fire detector, was added to the test series for evaluation purposes. The particular detector chosen is equipped with a meter which gives an analog indication of the detectors's shift towards alarm threshold. The detector also includes an alarm horn within the detector enclosure which sounds an alarm when the appropriate threshold is reached.

\section{EXPERIMENTAL PROCEDURES AND MATERIALS}

\subsection{Fire Test Room}

The fire test series was conducted in UL's east fire test room. This room is a large open space $18 \mathrm{~m}$ by $18 \mathrm{~m}$ (60 ft by $60 \mathrm{ft}$ ) by $5 \mathrm{~m}$ $(15.75 \mathrm{ft})$ high. The test fires were positioned $1.2 \mathrm{~m}(3.75 \mathrm{ft})$ off the floor or about $3.7 \mathrm{~m}(12 \mathrm{ft})$ below the ceiling. The smoke detectors were placed on the ceiling approximately $6.4 \mathrm{~m} \mathrm{(21} \mathrm{ft)} \mathrm{from} \mathrm{the} \mathrm{point} \mathrm{directly}$ over the fire center, which corresponds approximately to a 9-meter (30-ft) spacing pattern for the detectors. (See fig. 1 for test room layout.) 


\subsection{Instrumentation}

The following measuring and recording equipment was employed during the test series.

\subsubsection{Smoke Density Measuring Equipment}

Two photometric units were used to measure the visible smoke obscuration/optical density. These were fastened to the ceiling. One was placed about 1.5 metres (five feet) from and parallel to a line joining the fire center and the detectors and the other was placed just in front of the detectors (see fig. 1). Each photometric unit consisted of a barrier-layer-type photoelectric cell spaced $1.5 \mathrm{~m}$ (five feet) from a tungsten filament, automotive-type spotlight energized from a constant voltage source. The output of the photocells was connected to a Honeywell, two-pen, chart recorder.

\subsubsection{Temperature Recording}

One thermocouple was placed directly over the fire and one was placed at the detectors' location. The temperatures were recorded on a Honeywe11, multipoint chart recorder.

\subsubsection{Carbon Monoxide}

Carbon monoxide concentrations in parts per million were continu-, ously monitored and recorded during all tests. A pickup tube was placed on the ceiling and positioned just in front of the detectors. This tube was connected to a CO monitor (Ecoloyzer Mode1 2400). The output of the monitor was connected to a strip-chart recorder.

\subsubsection{Detector Actuation}

The time of detector actuation was recorded on a 25-clock annunciator panel which indicated detector operation to the nearest second. Electrical signals were taken from the single-station smoke detectors' alarm horn circuitry and these signals were used to stop the respective detector's clocks. The normally-open relays within the commercial detectors were used to stop their respective clocks.

\subsection{Test Materials}

The test fire included six different materials of which the first four were those specified in UL Standard No. 167. A description of the test fire materials follow. 


\subsubsection{Shredded Paper}

This test fire consisted of $227 \mathrm{~g}(1 / 2 \mathrm{lb})$ of newsprint torn in strips approximately $0.95 \mathrm{~cm}$ (3/8 in) wide and 15 to $61 \mathrm{~cm}$ (6 to 24 in) long. The paper strips were placed in a cylindrical receptacle $0.64 \mathrm{~cm}$ ( $1 / 4$ in) mesh hardware cloth. The overall dimensions of the receptacle were $30 \mathrm{~cm}$ (12 in) round by $61 \mathrm{~cm}$ (24 in) high with a hardware-cloth bottom positioned $15 \mathrm{~cm}$ ( 6 in) above the base. The paper was fluffed up in such a way as to produce a significant volume of smoke before open flaming took place. Ignition was by a kitchen match applied to the bottom center of the basket.

\subsubsection{Polystyrene}

Fifty-seven grams (2 oz) of spagetti-type, foamed, polystyrene packing material, with no flame inhibitor, was placed in the same wire basket used for the shredded paper fire tests. The polystyrene was ignited by $50 \mathrm{cc}$ of ethyl alcohol placed in a pan positioned under the bottom center of the basket.

\subsubsection{Gasoline}

Two hundred cubic centimeters (200 cc) of regular, leaded motor gasoline was placed in a $23-\mathrm{cm}$ (9-in) diameter, steel pan, $3.8 \mathrm{~cm}(1-1 / 2$ in) deep. Ignition was by common match. The gasoline in the pan was kept covered, to prevent evaporation, until ignition.

\subsubsection{Wood Brand (UL Class A)}

The UL Class A wood brand is a wood crib composed of three layers of kiln-dried, Douglas fir, wood strips. Each strip was $1.9 \mathrm{~cm}(3 / 4 \mathrm{in})$ square by $30 \mathrm{~cm}$ (12 in) long. Twelve strips were used for each layer and were stapled together. Each layer was placed at right angles to adjacent layers. Overall dimensions of the wood cribs were $30 \times 30 \times 6 \mathrm{~cm}$ (12 $\mathrm{x}$ $12 \times 2-1 / 4 \mathrm{in}) \mathrm{high}$. The crib was ignited by $100 \mathrm{cc}$ of denatured alcohol consisting of $95 \%$ ethanol and $5 \%$ methanol. The alcohol was contained in the same pan as used for the gasoline test fire.

\subsubsection{Cotton}

Approximately $900 \mathrm{~g}$ (2 1bs) of raw cotton was placed in a 30-cm (12in) square pan and placed on a 1000-watt, 120 VAC, hot plate. 


\subsubsection{Polyurethane}

Pieces of flexible polyurethane foam, $30 \times 30 \times 8 \mathrm{~cm}(12 \times 12 \times 3$ in) were placed in a pan constructed of aluminum foil. The pan was shaped to fit snugly around the base of the foam pieces. The sides of the pan flared out slightly and were about $8 \mathrm{~cm}$ ( $3 \mathrm{in}$ ) high. The polyurethane foam was ignited by $10 \mathrm{cc}$ of ethyl alcohol, poured into the pan along one side of the foam. Ignition of the alcohol was by kitchen match.

The materials and the quantities used produced fires of similar burning time and smoke buildup rates with the exception of the smoldering cotton test. In this test, a considerably longer time was necessary to develop sufficient smoke at the detector site for detection. Whereas all the other test fires were essentially complete in about five to six minutes, the smoldering cotton fire was allowed to run about 40 minutes.

\subsection{Smoke Detectors}

Eleven detectors were included in the test series. Eight were photoelectric smoke detectors, two were ionization chamber smoke detectors, and one was a detector employing a semiconductor gas sensor commonly known as a Taguchi gas sensor (TGS). A list of all the detectors used in the test series along with their pertinent operating characteristics will be found in table 1 .

The ceiling-mount detectors were fastened to $2.5 \times 20 \mathrm{~cm}$ ( 1 in $\times 8$. in) wood boards. These boards were then affixed to the ceiling approximately $6.4 \mathrm{~m}$ (21 ft) horizontally from the point above the center of the test fires. For the three wall-mount detectors, $2.5 \times 20 \mathrm{~cm}$ ( 1 in $\times 8$ in) wood boards, approximately $20 \mathrm{~cm}$ ( $8 \mathrm{in}$ ) long, were fastened in a vertical position to the ceiling boards. The detectors were then positioned on the vertical board surfaces in an approximation of a wall-mount position. The wall-mount detectors were placed so that the ends of the detectors faced towards the smoke flow from the test fires.

\subsection{Test Procedures}

The procedure used in nearly all of the test fires was to ignite the test material and allow the material to be completely consumed while continuously recording the smoke density at the ceiling on the two smoke density units and the carbon monoxide levels at the detector locations. The maximum temperatures over the fire and at the detector locations were recorded as well as the alarm trip points for the detectors. The velocity of the smoke along the ceiling was calculated by averaging the time taken by the smoke front to pass from the first smoke density measuring unit to the second unit. Each test was terminated when it was apparent the smoke had dropped below detectable levels. The test room was then ventilated and all products of combustion removed from the room. All detectors and test apparatus were then reset for the next test. 


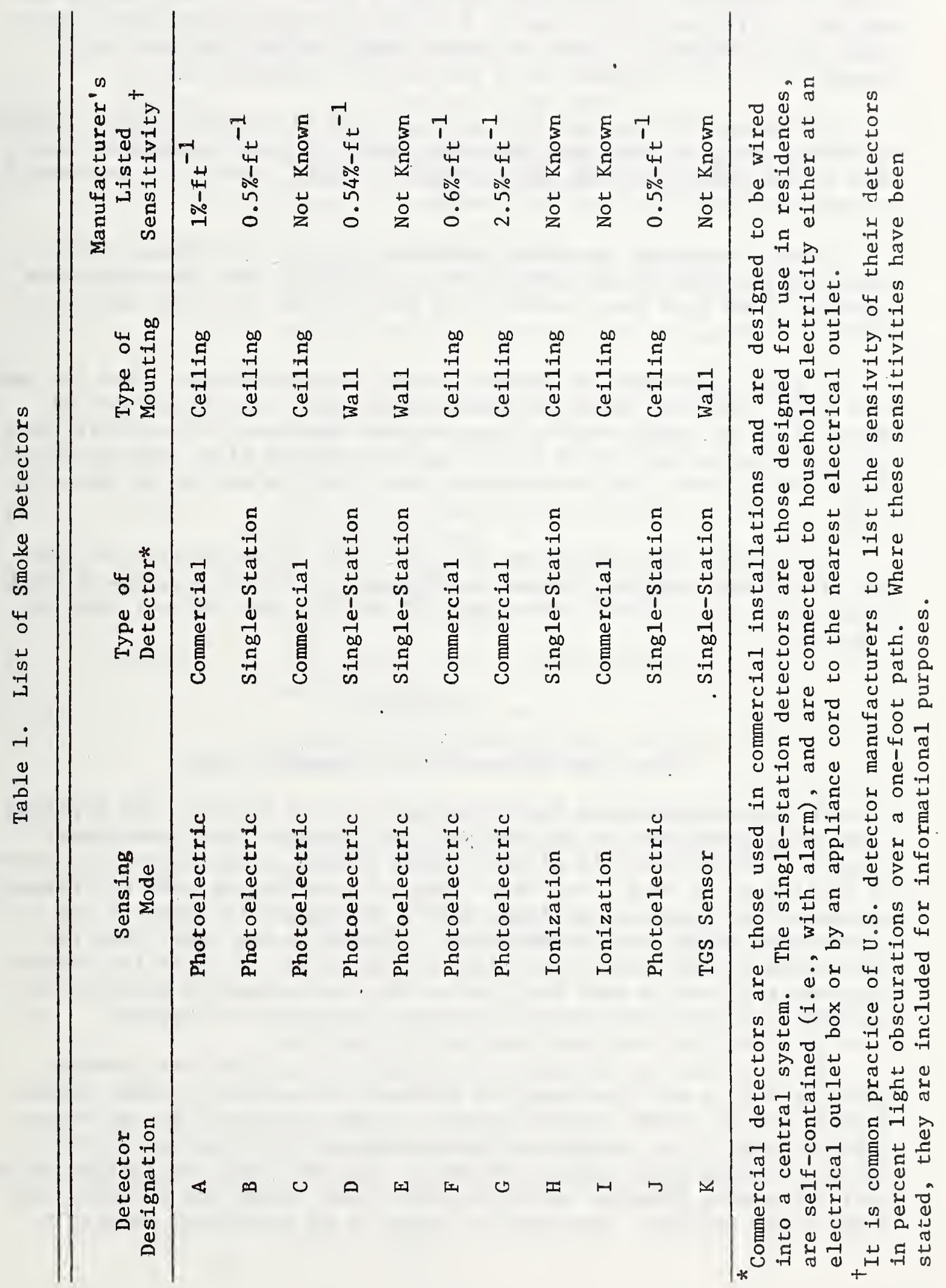




\section{RESULTS}

The results of 26 test fires are reported on herein. The test fires are numbered sequentially from No. 1 to No. 27 . Test No. 18 was omitted. This test, which was of a fire-retardant-treated polyurethane foam, was a failure in terms of smoke output as the fire went out immediately after consumption of the alcohol ignition fuel.

The 26 test fires have been grouped into 13 test series for clarity purposes; tests of identical materials under the same conditions have been listed under one test series number. Table 2 gives the regrouping of the test fires into the test series.

Table 3 presents the alarm response times of the various smoke detectors for each of the test fires. In table 4, the detector alarm response times have been regrouped by test series to follow table 2's format.

Figures la through 26 present the following pertinent data for each test fire: detector alarm response times; smoke density buildup as measured by the light beam in front of the detectors; type of fire and ignition source; maximum $C O$ levels at the detector site; average velocity of the smoke front; and temperatures over the fire and at the detector site.

Only those smoke detectors that were able to detect most of the test fires are shown on figures la through 26. Therefore, due to inadequate detection response, detectors " $J$ " and " $K$ " were omitted from the figures.

\section{DISCUSSION}

\subsection{Test Series No. 1 - Shredded Paper}

This series included test fire Nos. 1,2, 3 and 10 . The shredded paper test series was quite difficult to reproduce with consistent results. While UL-167 is silent on this point, the shredded paper must be fluffed up in such a way as to burn in a smoldering mode for several seconds after the match ignition before bursting into flame if any appreciable smoke is to be produced. If this is not done, then the paper immediately bursts into flame and little or no smoke is produced. This was the case in test No. 2 where the two ionization chambers and one photoelectric detector were the only detectors to respond.

The procedure UL follows in this test is to fluff the shredded paper in such a way that smoke is produced for several seconds before flaming begins. When flaming begins, a hole is punched in the smoke cloud causing it to resemble a large doughnut. The thermal energy of the now flaming paper pushes the smoke ring out along the ceiling in an ever increasing diameter until the smoke ring passes the detector location on the ceiling. The pulse of smoke is of sufficient density to 
Table 2. Description of Test Fires

\begin{tabular}{|c|c|c|}
\hline $\begin{array}{l}\text { Test } \\
\text { Series }\end{array}$ & $\begin{array}{l}\text { Test } \\
\text { Numbers }\end{array}$ & Types of Test Fires \\
\hline$\# 1$ & $1-2-3-10$ & $\begin{array}{l}227 \mathrm{~g}(8 \mathrm{oz}) \text { of shredded paper in hard- } \\
\text { ware cloth basket. Match ignited in bottom } \\
\text { center. }\end{array}$ \\
\hline$\# 2$ & $8-9-27$ & $\begin{array}{l}57 \mathrm{~g}(2 \mathrm{oz}) \text { of polystyrene packing } \\
\text { material, ignited by } 50 \mathrm{cc} \text { of ethyl alcohol. }\end{array}$ \\
\hline 非 3 & 6 & $100 \mathrm{cc}$ of motor gasoline, match ignition. \\
\hline \#4 & 7 & $200 \mathrm{cc}$ of motor gasoline, match ignition. \\
\hline \# 5 & $4-5$ & $\begin{array}{l}\text { Class A wood brand ignited by } 100 \text { cc of } \\
\text { ethyl alcohol. }\end{array}$ \\
\hline \#6 & $11-12$ & $\begin{array}{l}\text { Two Class A wood brands ignited by } 100 \mathrm{cc} \\
\text { of ethyl alcohol. }\end{array}$ \\
\hline \# 7 & $13-14-21$ & $\begin{array}{l}\text { Two Class A wood brands ignited by } 25 \mathrm{cc} \\
\text { of ethyl alcohol. }\end{array}$ \\
\hline \#8 & $22-23$ & $\begin{array}{l}\text { One Class A wood brand ignited by } 10 \mathrm{cc} \text { of } \\
\text { ethy! alcohol. }\end{array}$ \\
\hline \#9 & 15 & $\begin{array}{l}\text { Class A wood brand on 1000-watt hot plate. } \\
\text { Immediate ignition, flaming fire. }\end{array}$ \\
\hline$\# 10$ & 16 & $\begin{array}{l}\text { Two } 30 \times 30 \times 8 \mathrm{~cm}(12 \text { in } \times 12 \text { in } \times 3 \text { in) pieces } \\
\text { of flexible polyurethane foam ignited by } 10 \mathrm{cc} \\
\text { of ethyl alcohol. }\end{array}$ \\
\hline 非11 & $17 A-19-24$ & $\begin{array}{l}\text { Three } 30 \times 30 \times 8 \mathrm{~cm}(12 \text { in } \times 12 \text { in } \times 3 \text { in) pieces } \\
\text { of flexible polyurethane foam ignited by } 10 \mathrm{cc} \\
\text { of alcohol. }\end{array}$ \\
\hline 非12 & $25-26$ & $\begin{array}{l}\text { One } 30 \times 30 \times 8 \mathrm{~cm} \text { ( } 12 \text { in } \times 12 \text { in } \times 3 \text { in) piece } \\
\text { of flexible polyurethane foam ignited by } 10 \mathrm{cc} \text { of } \\
\text { ethyl alcohol. }\end{array}$ \\
\hline \#13 & 20 & $\begin{array}{l}\text { Raw cotton, } 907 \mathrm{~g}(2 \mathrm{lbs}) \text {, in pan on } \\
1000 \text {-watt hot plate. }\end{array}$ \\
\hline
\end{tabular}


Table 3

Detector Alarm Response - In Seconds

\begin{tabular}{|c|c|c|c|c|c|c|c|c|c|c|c|}
\hline \multicolumn{12}{|c|}{ Detectors } \\
\hline $\begin{array}{l}\text { Test } \\
\text { No. }\end{array}$ & 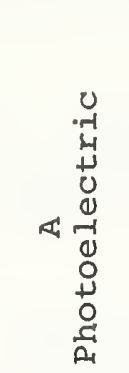 & 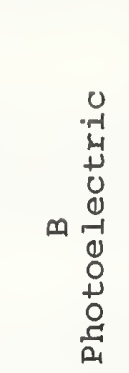 & 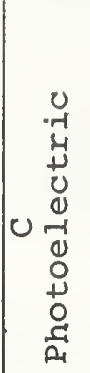 & 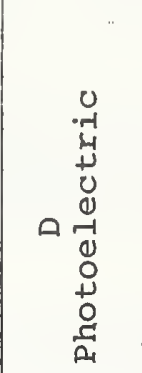 & 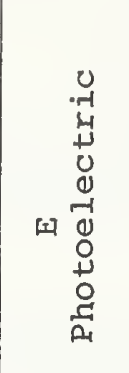 & 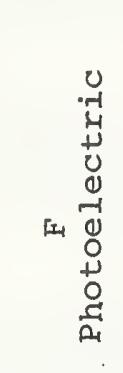 & 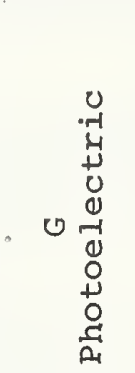 & 江莣 & 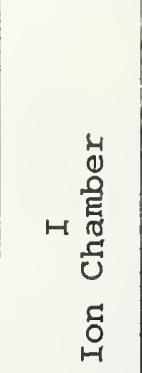 & 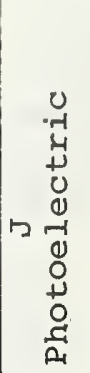 & 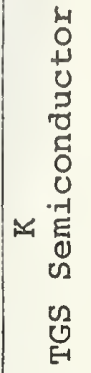 \\
\hline 1 & 30 & 46 & 27 & 29 & 28 & 36 & 34 & 33 & 30 & 56 & 36 \\
\hline 2 & --- & 29 & -- & -- & --- & -- & -- & 32 & 27 & -- & -- \\
\hline 3 & 28 & 30 & 26 & 28 & 27 & 32 & 31 & 30 & 27 & -- & --- \\
\hline 4 & --- & 45 & $\cdot--$ & --- & -- & --- & --- & 45 & 38 & --- & --- \\
\hline 5 & --- & 42 & -- & --- & --- & 41 & --- & 45 & 35 & -- & --- \\
\hline 6 & 62 & 52 & 55 & 72 & 58 & 57 & 107 & 44 & 39 & -- & --- \\
\hline 7 & 63 & $5 \overline{5}$ & 76 & 76 & 59 & 64 & 132 & 46 & NR & -- & -.- \\
\hline 8 & 44 & 52 & 42 & 46 & 42 & 44 & 41 & 42 & 31 & --- & --- \\
\hline 9 & 34 & 30 & 31 & 36 & 30 & 41 & 34 & 32 & NR & -- & --- \\
\hline 10 & 28 & 28 & 27 & 28 & 28 & 34 & 31 & 30 & 28 & -- & -- \\
\hline 11 & 49 & 51 & 53 & 58 & 58 & 49 & --- & 52 & 43 & -- & -- \\
\hline 12 & 48 & 56 & 49 & 55 & * & 51 & 46 & 49 & 47 & -- & -- \\
\hline 13 & 49 & 49 & 54 & 119 * & 52 & 4.7 & 70 & 47 & 44 & -- & -- \\
\hline 14 & 47 & 53 & 88 & * & 63 & 49 & 45 & 53 & 46 & -- & --- \\
\hline 15 & --- & --- & $=-$ & * & --- & -- & --- & 139 & 113 & -- & --- \\
\hline 16 & 156 & 103 & 162 & * & 138 & $13 * 4$ & $\cdot---$ & 90 & 109 & --- & --- \\
\hline $17 \mathrm{~A}$ & 154 & 108 & 163 & * & 138 & 170 & --- & 85 & $108:$ &.-- & --- \\
\hline 19 & 123 & 102 & 124 & * & 124 & 119 & 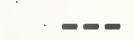 & 97 & 109 & --- & --- \\
\hline 20 & 1,656 & 1,582 & --- & 1,754 & 1,762 & 1,632 & 1,690 & -- & 1,654 & -- & IND \\
\hline 21 & 74 & 67 & 76 & 103 & 111 & 74 & 74 & 72 & 73 & 160 & --- \\
\hline 22 & 103 & 97 & 103 & 130 & 118 & 102 & 103 & 106 & 110 & -- & --- \\
\hline 23 & 96 & 92. & 101 & 124 & 102 & 100 & 95 & 102 & 101 & --- & --- \\
\hline 24 & 138 & 111 & 141 & 134 & 136 & 138 & --- & 92 & 114 & -- & --- \\
\hline 25 & 134 & 109 & 145 & 134 & 132 & 141 & --- & 104 & 120 & -- & --- \\
\hline 26 & 127 & 137 & 138 & 131 & 133. & 134 & --- & 118 & 113 & -- & --- \\
\hline 27 & 51 & 51 & 52 & 55 & 54 & 58 & --- & 50 & 48 & -- & --- \\
\hline
\end{tabular}

Note: --- No alarm or indication

IND Indication but no alarm

* Clock timer malfunction

NR Not resettable 
Table 4. Detector Alarm Response

- In Seconds Arranged by Test Series

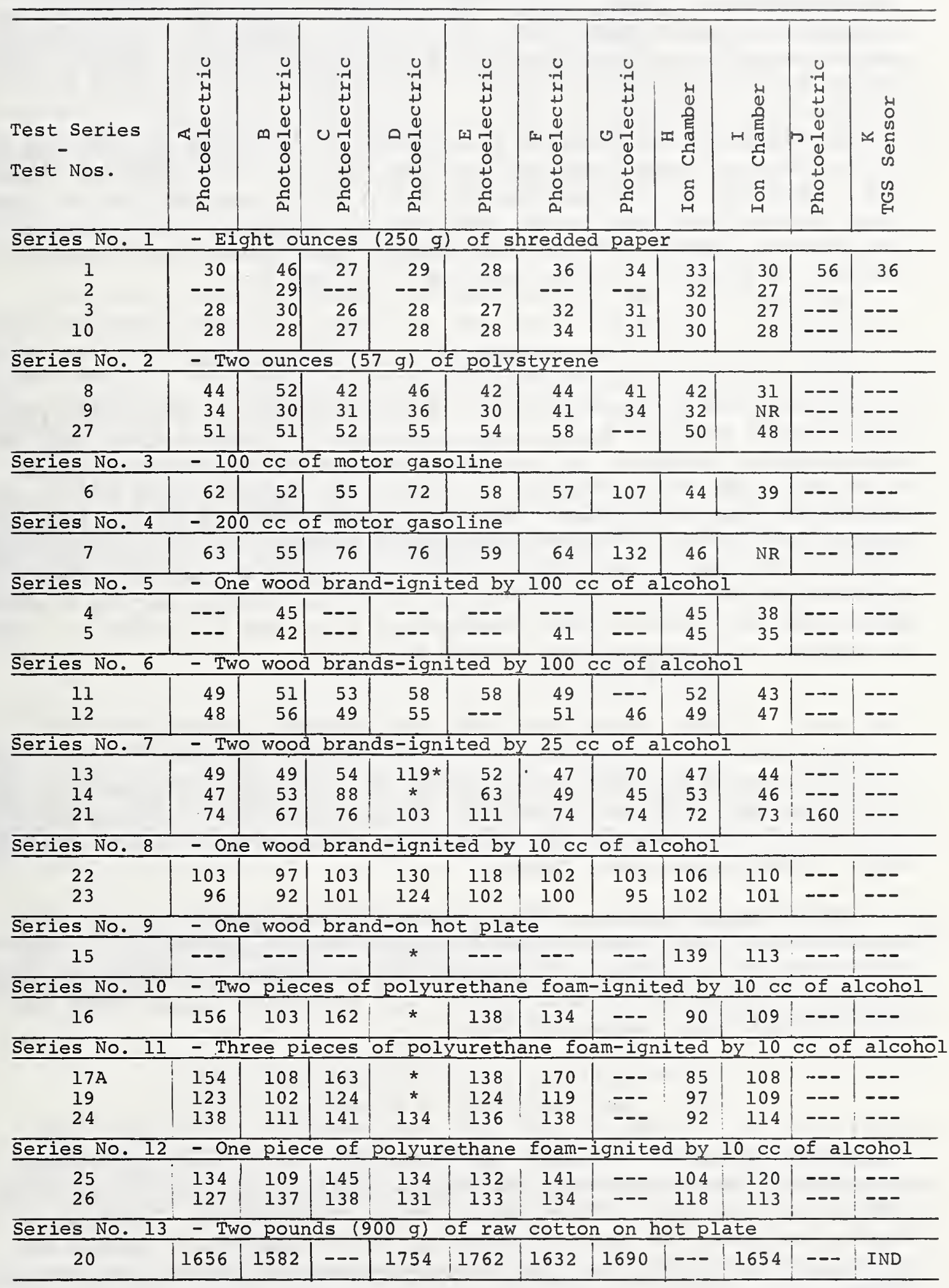

Note: --- No alarm or indication

IND Indication but no alarm

* Clock timer malfunction

NR Detector not resettable 
operate the better photoelectric smoke detectors. In the test series, the Ionization smoke detectors were probably responding more to the submicron (nonvisible) smoke particles coming from the flaming combustion than to the visible smoke. In one test, which was discarded, the shredded paper went immediately into flaming combustion, with negligible production of smoke, and only the two ionization chamber smoke detectors responded to this fire.

In figure 10, which shows the results of fire test No. 10, the peak of the smoke is shown occurring about 45 seconds after detector actuation. Problems were encountered in starting the recorder for the smoke density meter precisely at the same time as ignition. This accounts for the 45-second offset. In all likelihood, this figure should have resembled the figures for fire test Nos. 1, 2 and 3.

\subsection{Test Series No. 2 - Polystyrene}

This series included test fire Nos. 8, 9 and 27. The polystyrene fires produce stringy, black smoke particles. It was thought that the photoelectric detectors, all of which operate on the scattered-light principle, might have problems with the black smoke because of its poor light-scattering properties. Such was not the case as can be seen in figures 8, 9 and 26. Only one photoelectric detector did not alarm and this was detector " $G$ " in test No. 27. This detector was the least sensitive of any of the photoelectric detectors tested, having a nominal sensitivity in terms of light obscuration of $8.2 \%-\mathrm{m}^{-1}\left(2.5 \% \mathrm{ft}^{-1}\right)$. This may explain its nonoperation in test No. 27.

\subsection{Test Series No. 3 - Gasoline - $100 \mathrm{cc}$}

This series included test fire No. 6. The $100 \mathrm{cc}$ of gasoline was a mistake in that it should have been $200 \mathrm{cc}$ per UL-167. Regardless of this, all of the photoelectric detectors responded well before the peak smoke concentrations were reached.

Open-burning gasoline fires produce copious quantities of sooty, black smoke as can be seen from the graph of the smoke buildup. The black smoke did not appear to pose a problem to the photoelectric smoke detectors although again detector "G" was slower to respond than the other photoelectric smoke detectors.

\subsection{Test Series No. 4-Gasoline - $200 \mathrm{cc}$}

This test series included test fire No. 7. The only difference between this test series and the one preceding is the use of $200 \mathrm{cc}$ of gasoline as opposed to $100 \mathrm{cc}$ in the prior test series. The peak smoke density was about the same although the total quantity of smoke, the average smoke velocity and the carbon monoxide maximum were slightly higher. 


\subsection{Test Series No. 5 - One Wood Brand}

This test series included test fire Nos. 4 and 5. The UL-167 requirement for ignition of this wood crib is by the use of $100 \mathrm{cc}$ of ethyl alcohol. As can be seen from the smoke graphs in figures 4 and 5 , there is very little visible smoke. As a consequence, only one of the photoelectric detectors responded in test No. 4 and only two photoelectric smoke detectors responded in test No. 5. Both of the ionization chamber detectors responded.

\subsection{Test Series No. 6 - Two Wood Brands}

This test series included test fire Nos. 11 and 12 . This test series differed from No. 5 above in that two wood brands (cribs) were used, one stacked on the other; in an attempt to produce additional visible smoke. As was expected, additional visible smoke was produced. It was sufficient to activate all of the photoelectric detectors, except detector " $G$ " in test fire No. 11.3

It was noted, during the course of this test, that the ignition source of $100 \mathrm{cc}$ of alcohol took more than 2 minutes to be consumed. It was apparent that the alcohol flames were consuming much of the visible smoke from the wood crib, particularly during early stages of the test fire.

\subsection{Test Series No. 7 - Two Wood Brands}

This test series included test fire Nos. 13, 14 and 21 . This test series was the same as test series No. 6 in that two wood brands were used. But instead of $100 \mathrm{cc}$ of alcohol as an ignition source, $25 \mathrm{cc}$ were used. The pan for the alcohol was reduced to $90 \mathrm{~mm}(3-1 / 4 \mathrm{in})$ diameter to prevent the flames from coming out around the edges of the wood crib.

As was expected, the quantity of visible smoke increased significantly. The quantity was sufficient to activate all of the photoelectric detectors except for detector " $D$ " (test fires 13 and 14) which had a faulty timer.

\subsection{Test Series No. 8 - One Wood Brand}

This test series included test fire Nos. 22 and 23 . In this series of tests, the decision was made to return to one wood brand and to use $10 \mathrm{cc}$ of alcohol in the smaller pan as the ignition source. The results, which are shown on figures 21 and 22, indicated a large increase in the

The difference between the detectors' response time and the smoke peak
was due to the timing problems previously noted under test series No. 1 . 
peak optical density of the smoke. In fact, the peak is similar to the peaks obtained with the shredded paper, except that those from the wood brands are not quite as sharp. All the photoelectric detectors responded well to this test serles.

\subsection{Test Serles No. 9 - Wood Brand on Hot Plate}

This test series included test fire No. 15. This test series was an attempt to produce smoldering combustion of the wood brand by placing It on a preheated hot plate. Unfortunately, the wood brand flamed Immediately as the hot plate surface was above the auto-ignition temperature for wood. Very little visible smoke was produced. As a result, only the two Ionization chambers responded.

\subsection{Test Series No. 10 - Polyurethane - Two Pieces}

This test included test fire No. 16. The test was an attempt to duplicate one of the test fires used in Europe to test smoke detectors.

The polyurethane flexible foam burned in a flaming mode producing a finely-divided black smoke. The bulldup and decay curve was one of the smoothest of all the test series. In this test series, the response time of the smoke detectors was spread more than in any of the other tests. "The photoelectric smoke detector "G" did not respond.

\subsection{Test Series No. 11 - Polyurethane - Three Pleces}

This test series included test fires 17A, 19 and 24. Three pieces of polyurethane flexible foam were burned in this test series as opposed to two in test series No. 10. It was anticipated that more visible smoke would be produced with three pieces of polyurethane as opposed to two. In test fire No. 17A, the quantity was somewhat larger, though the peak or maximum optical density of the smoke was about the same as with two pieces of polyurethane. The spread of alarm times for the detectors was also similar to test serles No. 10 with two pieces of polyurethane.

In test fire Nos. 19 and 24 both a greater quantity of smoke and a higher peak optical density were observed. Another type of polyurethane foam was used in test fire Nos. 19 and 24 as opposed to test fire No. $17 \mathrm{~A}$.

At the time of the tests, It was thought that the two polyurethane foam types were equivalent. But a close analysis of the results indicates the second polyurethane foam (test fire Nos. 19 and 24) may have produced more smoke than the first foam (test fire No. 17A).

Again, as in test serles No. 10, the photoelectric smoke detector " $G$ " did not respond. It can be reasonably deduced that the concentration 
of the black smoke within the detector sensing chamber of this detector was not sufficient to produce alarm response.

\subsection{Test Series No. 12 - Polyurethane - One Piece}

This test series includes test fire Nos. 25 and 26 . In this test series, only one piece of polyurethane flexible foam was used. The maximum optical density of the smoke produced was similar to the preceding tests though the quantity was less. The response of the detectors was similar also, and again, photoelectric detector "G" did not respond.

\subsection{Test Series No. 13 - Smoldering Cotton}

This test included test fire No. 20. In this series, an attempt was made to produce a test fire of smoldering cotton by heating a quantity of raw cotton in a pan on a hot plate. It has been reported [5] that in this type of fire, photoelectric smoke detectors are significantly quicker to respond than ionization chamber smoke detectors.

It was quite difficult to produce detectable quantities of smoke from the smoldering cotton at the detector site. At first, the smoke from the cotton layered about halfway to the ceiling. Finally, after 25 minutes or so, the smoke began to rise to the ceiling and move out towards the detectors.

The results are interesting. First, the response times of the detectors were spread out significantly. The two wallmount, singlestation photoelectric detectors " $D$ " and " $E$ " were the slowest to respond. All photoelectric smoke detectors, with the exception of "C", ultimately responded. Detector " $C$ " uses a light source for detection which lies in the infrared wavelength while all of the other photoelectric detectors have light sources in the visible region of the electromagnetic spectrum. This may have had some effect on its response to the smoke from the smoldering cotton.

One of the ionization chamber smoke detectors did not respond. This was detector " $\mathrm{H}$ " which is a single-station, residential variety of detector. Somewhat unexpectedly, the other ionization chamber smoke detector did respond and only shortly after the two most sensitive photoelectrics. One possible explanation for this is that the detector was set near its most sensitive setting. This, coupled with the fact that this detector is one of the more sophisticated ionization chamber smoke detectors on the U.S. market, may have accounted for its good responsiveness to the smo1dering cotton fire. 


\subsection{Carbon Monoxide}

As described in paragraph 2.2.3., peak carbon monoxide concentrations were recorded at the detector location. These measurements were taken for future correlation. In the shredded paper fire tests (Nos. 1, 2, 3 and 10), there appears to be a direct correlation between the peak carbon monoxide concentrations and the quantity of smoke produced.

This relationship is again apparent in the single wood brand tests. In tests 4 and 5, where $100 \mathrm{cc}$ of alcohol was used as the igniter, 11ttle smoke was produced and the peak CO averaged $50 \mathrm{ppm}$. In tests 22 and 23, where $10 \mathrm{cc}$ of alcohol was used as the igniter, much more smoke was produced and peak CO averaged $122 \mathrm{ppm}$. In the tests with two wood brands, the first series with $100 \mathrm{cc}$ of alcohol (tests 11 and 12) and the second series with $25 \mathrm{cc}$ of alcohol (tests 13, 14 and 21), there were no significant differences in the peak $\mathrm{CO}$ concentrations. The reason for this is not known.

Very little co was produced in the polystyrene tests. Peak Co concentrations ranged from 15 to $18 \mathrm{ppm}$. In these tests only $57 \mathrm{~g}$ ( $2 \mathrm{oz}$ ) of polystyrene was consumed. This may have been a factor in the low peak Co concentrations. No significant trends were noted in the peak $\mathrm{CO}$ concentrations recorded in the other tests.

From time to time, the question arises as to how effective a fire detector would be based on carbon monoxide sensing as opposed to detection of smoke particulates as done by conventional smoke detection. Assuming first that a carbon monoxide detector for home use can be developed that would be both practical and cost competitive with conventional smoke detectors, the next question would be what sensitivity range would be necessary. Looking at the results of the fire tests, peak co concentrations ranged from $15 \mathrm{ppm}$ to $125 \mathrm{ppm}$. The lowest co peaks were recorded in the polystyrene fires and the highest in the single wood brand fires using $10 \mathrm{cc}$ of alcohol as the ignition source.

Reports of ambient Co background levels have indicated levels in excess of $25 \mathrm{ppm}$ are present in some of our urban areas. In view of this, a lower sensitivity level of $50 \mathrm{ppm}$ for a co detector seems like a good place to start.

Fourteen of the 26 fires or 54 percent, generated $C 0$ peaks in excess of $50 \mathrm{ppm}$. This means that 46 percent of the test fires would not have been detected with a $\mathrm{CO}$ detector set at a $50 \mathrm{ppm}$ alarm point. Ignoring detectors " $J$ " and " $K$ ", the performance of the poorest photoelectric detector was detection of 14 fires or 54 percent. The best photoelectric detector performance was 25 of the 26 fires or 96 percent. The poorest performing ionization chamber detector detected 25 of the 26 fires or 96 percent. 
Assuming an alarm point of $25 \mathrm{ppm}$ for the carbon monoxide detector, such a detector would have detected 19 of the 26 test fires or 73 percent. A CO detector set at an alarm point of $25 \mathrm{ppm}$ therefore would have a detection capability comparable to most of the photoelectric smoke detectors tested in this program with regards to these test fires. Coupled with this increased responsiveness would be a possible problem of an increased number of false alarms to urban ambient co levels. But it would appear that a sensitive co detector may be effective as a home smoke detector, at least based on the types of fires conducted for this test series.

\subsection{Average Air Velocities}

The average air velocities ranged from a low of $5.2 \mathrm{~m} / \mathrm{min}$ (17 ft/min) for the single wood brand, $10 \mathrm{cc}$ alcohol tests (tests 22 and 23) to a high of $42.7 \mathrm{~m} / \mathrm{min}(140 \mathrm{ft} / \mathrm{min}$ ) for the wood brand on the hot plate (test 15 with wood brand flaming). On the whole, the average air velocities recorded were higher than had been anticipated.

It is interesting to note that the average air velocities for the four types of fires used by UL for judging detectors under UL-167 were: shredded paper, $18.3 \mathrm{~m} / \mathrm{min}$ (60 ft/min); wood brand, $12.2-21.3 \mathrm{~m} / \mathrm{min}$ ( $40-$ $70 \mathrm{ft} / \mathrm{min}$ ); gasoline, $15.9 \mathrm{~m} / \mathrm{min}$ (52 ft/min); and polystyrene, 18.3-21.3 $\mathrm{m} / \mathrm{min}(60-70 \mathrm{ft} / \mathrm{min})$. Work at the National Bureau of Standards has indicated that velocities of these orders are usually sufficient to overcome the smoke entry problems of most smoke detectors.

A note of caution is in order here. The method of measuring the average air velocity past the detectors was not designed to be very accurate. As described in section 2.5, the method used to determine the average air velocity was to time the smoke front between the two smoke density photometric units. The average air velocities are approximations and should be treated accordingly.

\subsection{Temperatures}

As described in section 2.2.2; the temperatures at the ceiling, directly over the fire and at the detector site, were recorded for each of the 26 test fires. Temperatures over the test fires ranged from a low of $18{ }^{\circ} \mathrm{C}\left(64^{\circ} \mathrm{F}\right)$ to a high of $50^{\circ} \mathrm{C}\left(122^{\circ} \mathrm{F}\right)$. Temperatures at the detector site ranged from a low of $12^{\circ} \mathrm{C}\left(54^{\circ} \mathrm{F}\right)$ to a high of $27{ }^{\circ} \mathrm{C}$ $\left(81^{\circ} \mathrm{F}\right)$. Ambient room temperatures during the test series ranged from $10^{\circ} \mathrm{C}\left(50^{\circ} \mathrm{F}\right)$ to $15^{\circ} \mathrm{C}\left(59^{\circ} \mathrm{F}\right)$. Fixed-temperature heat detectors have a nominal setting of between $54^{\circ} \mathrm{C}$ to $60^{\circ} \mathrm{C}\left(130^{\circ} \mathrm{F}\right.$ to $\left.140{ }^{\circ} \mathrm{F}\right)$. From the temperature data recorded, it is apparent that the temperatures generated both over the fire and at the detector site would not have been sufficient to operate a fixed-temperature heat detector, but most of the photoelectric and ionization chamber smoke detectors were able to detect nearly all of the fires. 


\subsection{Photoelectric Smoke Detector "J"}

Photoelectric smoke detector " $J$ " was a single-station smoke detector, approved by UL under UL-168 [2]. Analysis of this detector at NBS has shown that it has great difficulty in accepting and sensing slow-moving smoke. It was included in the test series in order to compare its performance against photoelectric smoke detectors having little or no smoke entry problems. In order to bias the results in favor of this detector, it's alarm threshold was set by the manufacturer at 0.5 percent per foot in terms of light obscuration. This setting was confirmed at NBS prior to and after the test series. The normal sensitivity setting of photoelectric smoke detectors is on the order of 1 to 2 percent per foot ( 3.3 to $\left.6.6 \%-\mathrm{m}^{-1}\right)$.

As can be seen from the tabulated results in table 3, this detector responded to only two of the 26 test fires (Nos. 1 and 21). It would appear from these results that photoelectric smoke detectors with significant entry problems would not be able to detect the types of fires utilized in this test series.

\section{SUMMARY AND CONCLUSIONS}

As described in section 1 , the purpose of the tests described in this report was to determine if photoelectric smoke detectors can respond to the four full-scale fires used by UL to evaluate ionization chamber smoke detectors. Seven of the eight photoelectric smoke detectors selected for the test series were chosen on the basis of their good response to slow-moving smoke under laboratory conditions, i.e., those detectors exhibiting little if any entry problems. The eighth photoelectric detector included in the test series detector "J", a detector which exhibits significant problems in sensing slow-moving smoke, was included for comparison purposes.

It was the opinion of the authors that the seven photoeletric smoke detectors could, in all likelihood, satisfactorily detect the four standard test fires, albeit, with perhaps some slight modifications to the test fires. If the results of the tests confirmed this opinion, then it should be possible to combine the requirements of UL-167 and UL-168 into one standard. One result of this combination of standards would be the new requirement for all photoelectric smoke detectors to detect the four fullscale fires before approval, a requirement now required of ionization chamber smoke detectors and all detectors using new sensing methods, other than the photoelectric principle.

If photoelectric detector " $J$ " had also managed to detect the four standard test fires, then either of two conclusions could have been drawn. One conclusion would have been that the standard test fires are not small enough to separate detectors with marginal performance from better performing detectors. The other conclusion would have been that 
the laboratory test procedures, which show large differences in the performance of various smoke detectors to slow-moving moving smoke, are not realistic as these differences are not reflected in the performance of detectors in real fire conditions.

Looking first at the shredded paper test series (test series No. 1 -test fires 1, 2, 3 and 10), all of the seven photoelectric detectors responded well within one minute, as did the two ion chambers, for test fires 1,3 and 10 . In test fire 2, very little smoke was produced as the paper flamed before significant quantities of smoke were produced. As a consequence, only photoelectric detector " $B$ " responded. As discussed earlier in this report, there is a problem in fluffing the shredded paper to produce a significant quantity of smoke after ignition, but prior to flaming of the paper. The photoelectric detector " $\mathrm{J}$ " and the TGS sensor " $\mathrm{K}$ " detected only test fire No. 1.

In the polystyrene test series (test series No. 2 -- test fires 8, 9 and 27), all seven of the photoelectric detectors and the two ionization chamber detectors responded within one minute except for photoelectric detector " $G$ " in test fire No. 27. This detector, while having very little entry problem, had the least sensitive setting of any detector. Test fire No. 27 required slightly longer detection times from all detectors and this may have had a bearing on the non-response of detector " $G$ ". The reason for the longer response time is not readily obvious as the smoke buildup was essentially the same in all three tests. Detectors "J" and " $K$ " did not alarm to any of the three polystyrene fires.

In the gasoline test fires (test fires 6 and 7), all seven photoelectric detectors as well as the two ionization chamber detectors responded in under two minutes except photoelectric detector " $G$ " in test fire No. 7 which responded in 132 seconds. Detectors " $J$ " and "K" did not respond.

Test fire No. 6 was with $100 \mathrm{cc}$ of gasoline although UL-167 specifies $200 \mathrm{cc}$. Test fire No. 7 was with $200 \mathrm{cc}$. No significant difference in detection times were noted between these two tests. In fact, the detectors' responses were slightly faster in the $100 \mathrm{cc}$ test than in the 200 cc test. The lack of difference is understandable as liquid fuel fires are surface-area-controlled fires. The result of adding additional fuel would be to lengthen the burning time and increase the total quantity of smoke but would have little effect on the peak smoke concentration or rate of buildup. The graphs of the smoke buildup appear to confirm this.

In the single wood brand test series (test series No. 5 -- test fires 4 and 5), only photoelectric detector " $B$ " was able to detect both fires. Photoelectric detector "F" was able to detect test fire No. 5, but not test fire No. 4. The reason for the non-response of the other photoelectric detectors is reasonably obvious from the graphs of the smoke buildup. Very little visible smoke was developed in these two tests. Slightly 
more smoke was produced in test fire No. 5 than test fire No. 4 and this. would account for the response of detector "F" to this latter test fire, but not to the former.

In an attempt to improve the performance of the photoelectric detectors to the wood brand fire, the number of wood brands was increased to two (test series No. 6 -- test fires 11 and 12). The ignition source of $100 \mathrm{cc}$ of alcohol remained the same. A bit more smoke was produced than with a single wood brand. This was sufficient to alarm all the seven photoelectric detectors except detector " $G$ " in test fire No. 11 and detector " $E$ " in test fire No. 12.

It was noted that the $100 \mathrm{cc}$ of alcohol burned for over two minutes. A careful scrutiny of the alcohol flames revealed that the flames were consuming the visible smoke coming from the burning wood brands. It was decided to reduce the quantity of the alcohol to $25 \mathrm{cc}$, but to retain the two wood brands. The results of this experiment are shown in test series No. 7 (test fires 13, 14 and 21). A greater quantity of smoke was produced with higher peak concentrations. As a result, all seven photoelectric detectors responded in under two minutes except for detector " $D$ " which was experiencing clock timer malfunctions.

It was decided to try one wood brand again. Instead of using $25 \mathrm{cc}$ of alcohol for ignition purposes, the quantity was reduced to $10 \mathrm{cc}$. The results are shown in test series No. 8 (test fires 22 and 23). With this combination, one wood brand, and $10 \mathrm{cc}$ of alcohol for ignition, some interesting results were obtained. The $10 \mathrm{cc}$ of alcohol provided a very low order ignition fire so that ignition of the wood was delayed for well over a minute. Then the wood brand began to generate profuse amounts of smoke for about thirty seconds. At this point open flaming was established and the visible smoke diminished. All seven photoelectric detectors responded within a 38-second interval and within 130 seconds from ignition of the alcohol.

The ionization chamber detectors responded throughout these series of experiments with the wood brands. Their margin of superiority, in terms of earlier response time, tended to diminish with decreasing amounts of the alcohol igniter which was, in turn, producing more visible smoke. This was to be expected.

Photoelectric detector " $J$ " responded to only one of the test fires in this wood brand sequence. TGS sensor " $K$ " did not respond to any of the wood brand fires and no indication was noted on its meter in any of these test fires.

With respect to the four tests specified in UL-167 and the response of photoelectric smoke detectors to these test fires: the following conclusions can be made. (1) Most presently available photoelectric smoke detectors would be unable to pass the wood brand fire test as presently specified in UL-167 because the test fire produces very little visible smoke. Since it is the purpose of the test to check response of detectors 
to wood smoke, and since a condition where the wood brand is forced into an immediate flaming mode by the alcohol is somewhat unrealistic in practice, It seems reasonable to modify the test to produce more visible smoke. If the wood brand test were modified, using less alcohol for ignition, as was done to these series of experiments, then more visible smoke would be produced. The results would be that many of the photoelectric detectors could then meet this test requirement. The suggested modification to this test to permit its use for evaluating photoelectric smoke detectors would be to continue with the one wood brand but reduce the alcohol igniter from $100 \mathrm{cc}$ to $10 \mathrm{cc}$. The size of the metal container for the alcohol should be reduced to a small, shallow pan having a diameter of approximately $90 \mathrm{~mm}(3-1 / 2 \mathrm{in})$. (2) The shredded paper test fires are extremely operator-dependent, as discussed in section 4.1. It is quite difficult to obtain repeatability between tests and it would be almost impossible to obtain reproducibility between laboratories. If the changes suggested above are made to the wood brand series, then the shredded paper test series may become redundant. Both the wood brand and the shredded paper test series are testing detector response to the same material, that is, to a burning cellulosic. (3) The gasoline test fire series of UL-167 is a satisfactory method, as now conducted, for the evaluation of photoelectric smoke detectors based on the results of experiments. Therefore, no modification is needed in this test series to accommodate photoelectric smoke detectors. (4) The polystyrene test fire series of UL-167, while satisfactory in terms of detectability by the photoelectric smoke detectors (with one exception), produced a smoke buildup at the detector location with two pronounced peaks. The reason for this is not known though it may be related to the use of $50 \mathrm{cc}$ of alcohol as an ignition fuel. Sufficient time was not available to investigate methods of producing a smoother smoke buildup such as experimenting with different quantities and configurations of alcohol ignition. The one exception mentioned above was detector " $\mathrm{G}$ " in test No. 27. As mentioned previously, this detector was the least sensitive of any of the photoelectric detectors tested. Although the detector has no appreciable smoke entry problem, it may be that it's preset sensitivity level was too high to detect the characteristically black smoke of polystyrene. (5) The polyurethane test fires were included in the test series as this material is used in several of the European countries as a standard test material for the evaluation of smoke detectors. The results were good enough to suggest the possibility of this material as a replacement for the polystyrene test material. Additional experiments will be necessary, however, to establish the quantity, configuration, specific type, and density of polyurethane to be used. In addition, it was apparent that in the experiments reported herein the detectors with sensitivities of less than $6.6 \%-$ $\mathrm{m}^{-1}\left(2 \% \mathrm{ft}^{-1}\right)$ will have difficulty with this test regardless of how excellently they respond to slow-moving smoke. (6) Photoelectric smoke detectors, found to have poor smoke entry characteristics at low air velocities, will respond to few, if any, of the UL-167 test fires. The example of this is the performance of detector " $\mathrm{J}$ ", a single-station smoke detector widely sold as a residential smoke detector. The detector was chosen as being representative of a class of photoelectric smoke detectors exhibiting 
poor response characteristics to slow-moving smoke when tested in laboratory-type smoke test tunnels. This suggests that the test fires used are sufficiently discriminatory in this regard and that the smoke entry characteristics measured in laboratory smoke test tunnels at low air velocities do give a reasonably accurate portrayal of the detector's response to real, but small fires (7) The lack of responsiveness of the one TGS sensor (detector "K") included in the test series to fires with relatively complete combustion should be noted. In open flaming fires, very little unburnt hydrocarbons and carbon monoxide are produced (the two main combustion products to which the TGS sensor is sensitive). It had been thought that the TGS sensor would respond to the smoldering cotton fire. But even here, only a slight analog output was noted which was far short of alarm threshold of the detector. (8) In order for a fire detector employing a carbon monoxide sensor to respond in a comparable manner to conventional smoke detectors, detection of $73 \%$ of the test fires would have been necessary. This would have required an alarm threshold to co of approximately $25 \mathrm{ppm}$. Since concentrations of $\mathrm{CO}$ in excess of this are periodically experienced in urban areas, a detector with this alarm threshold might experience an undue number of false alarms. (9) In tests where open flaming and little visible smoke predominated, the ionization smoke detectors demonstrated their superiority over photoelectric smoke detectors. In those tests where open flaming and significant quantities of visible smoke were produced simultaneously, neither type of detector indicated any significant margin of superiority. In the one truly smoldering fire, the photoelectric smoke detectors demonstrated their superiority over ionization smoke detectors to this type of fire. The obvious conclusion is that neither detector does well on all types of fires in terms of early response. If one could predict with some measure of certainty the type of fire to be given emphasis for detection, the appropriate detector could be selected. If this prediction is not practical, then either type of detector should be able to satisfy the detection needs. The choice of which to use in this case has to lie with other considerations, such as cost, reliability, esthetics, and the like.

\section{ACKNOWLEDGEMENTS}

The authors wish to thank Underwriters' Laboratories for making their smoke detector test facilities available for the test work. The authors gratefully acknowledge the assistance of Robert Pettinger and Harold Davidson of UL's staff in conducting the test series.

\section{REFERENCES}

[1] Custer, R. L. P. and Bright, R. G., Fire Detection: The State-ofthe-Art, Nat. Bur. Stand. (U.S.), Tech. Note 839, (June 1974) U.S. Government Printing Office., Washington, D.C., SD Cat. No. C13.46: $839 ; \$ 1.25$. 
[2] Standard for Smoke Detectors, Photoelectric Type, for Fire Protective Signaling Systems, UL-168, Underwriters" Laboratorles, Inc., Northbrook, I1. 60062 (March 31, 1971) - Also as ANSI A131.41971, American National Standards Institute, 1430 Broadway, N.Y. 10018.

[3] Standard for Smoke Detectors, Combustion Products Type, for Fire Protective Signaling Systems, UL-167, Underwriters' Laboratories, Inc., First Edition, November 29, 1974.

[4] Bukowski, R.W. and Bright, R.G., Some Problems Noted in the Use of Taguchi Semiconductor Gas Sensors as Residential Fire/Smoke Detectors, Nat. Bur. Stand. (U.S.), NBSIR 74-591, (Dec. 1974).

[5] Custer, R. L. P., Detector Actuated Automatic Sprinkler Systems A Preliminary Evaluation, Nat. Bur. Stand. (U.S.), Tech. Note 836, (July 1974), U.S. Government Printing Office, Washington, D.C., SD Cat. No. C13.46: 836, \$0.65. 


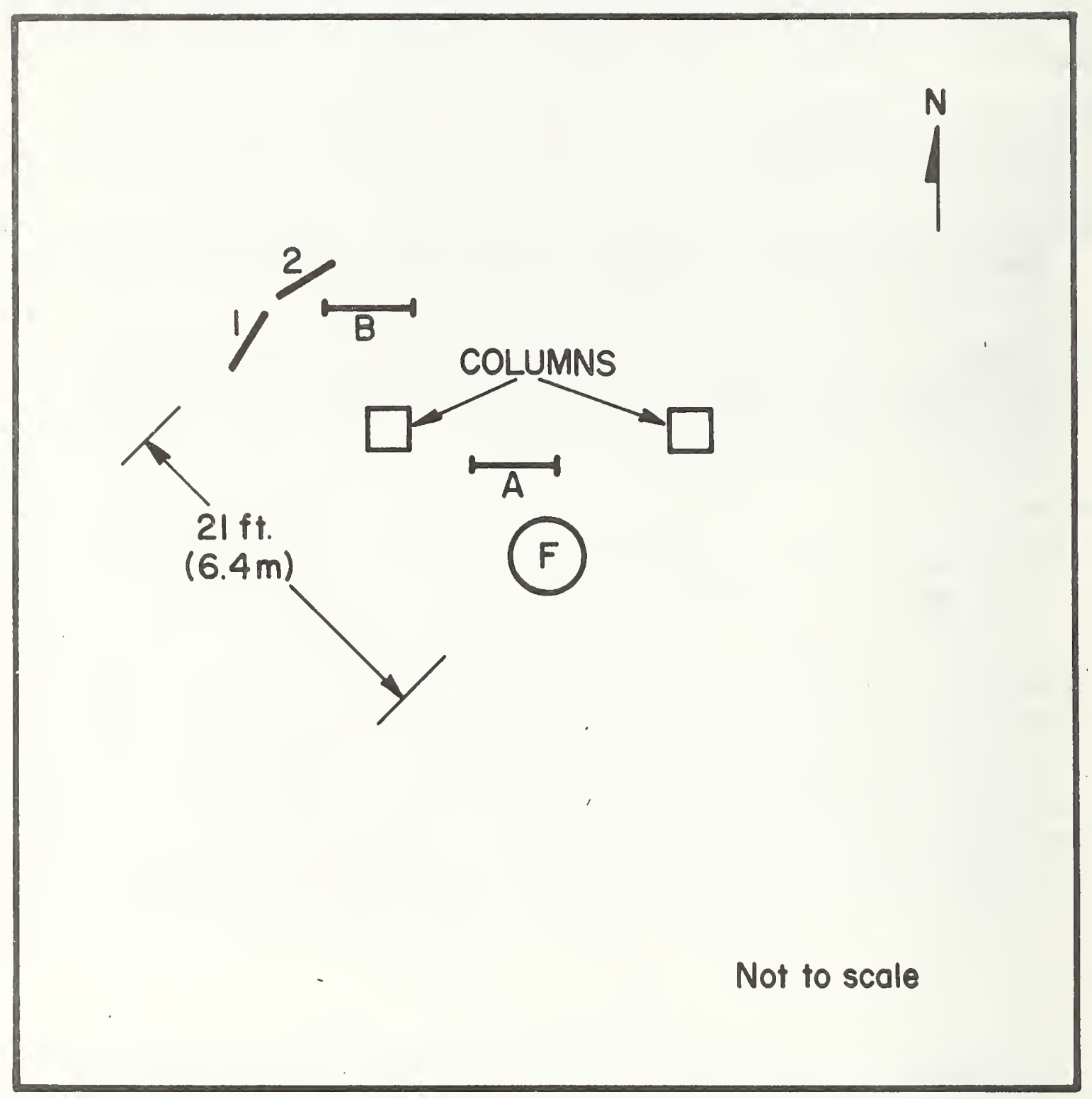

Notes:

1,2 Detector Board Locations

A, B Smoke Density Measuring Equipment

$F$ Fire Location

Figure 1. Fire test room floor plan. 


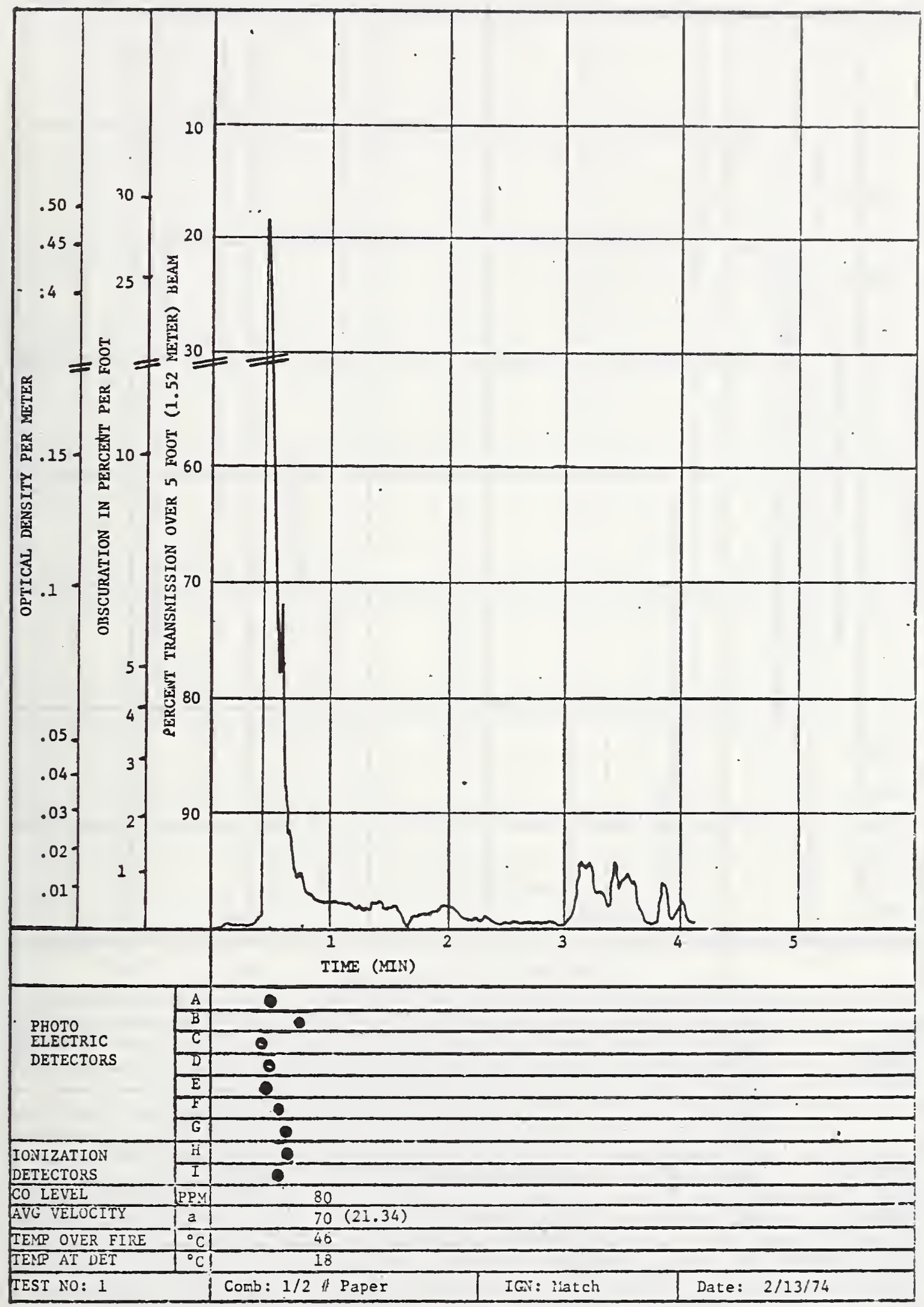

a. VELOCITY IN FEET PER MIN (METERS PER MIN)

Figure 1a. Results of fire test No. 1. 


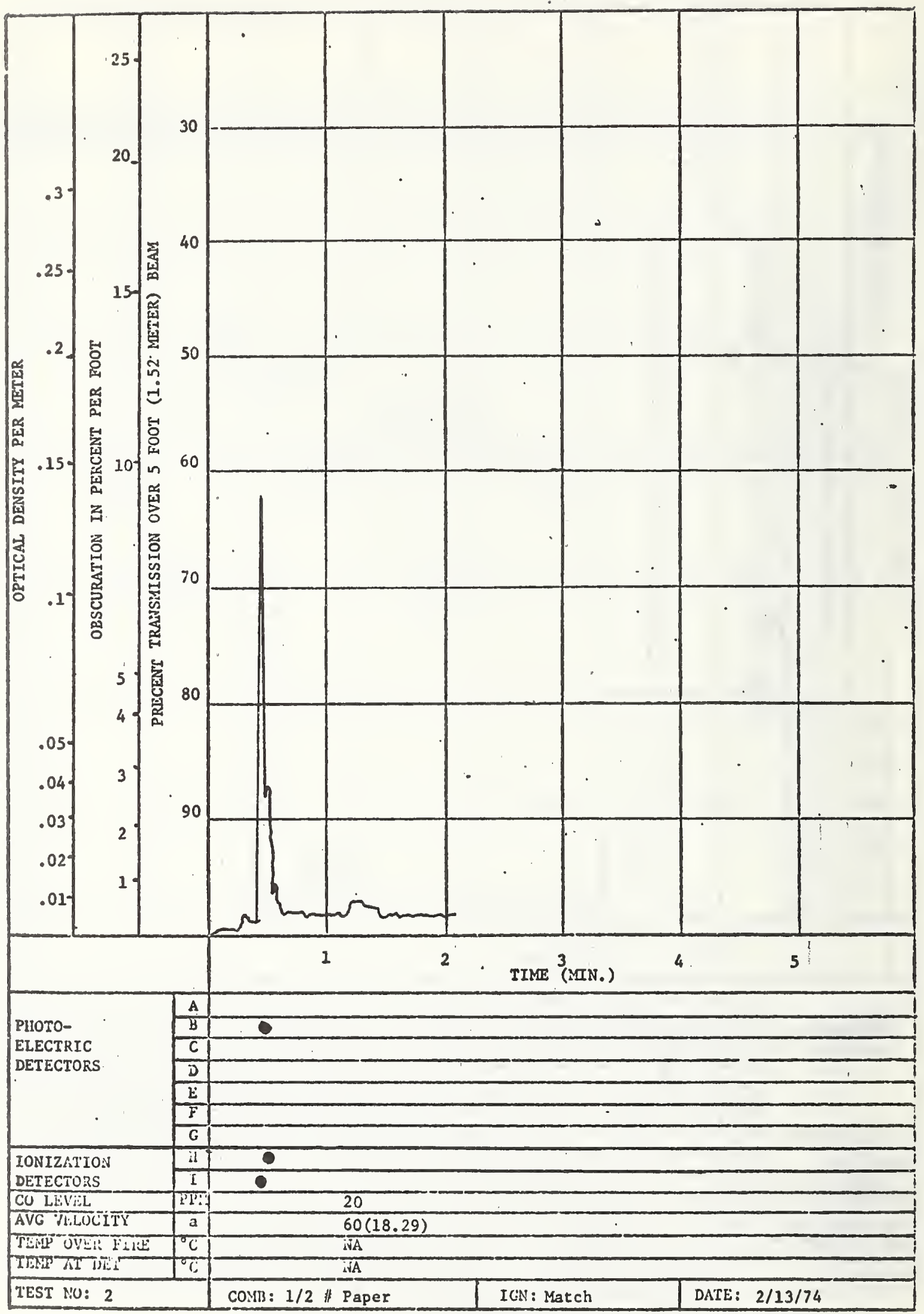

a. VELOCIIY IH FLET PLI HIH (METERS PER MIY:)

Figure 2. Results of fire test No. 2. 


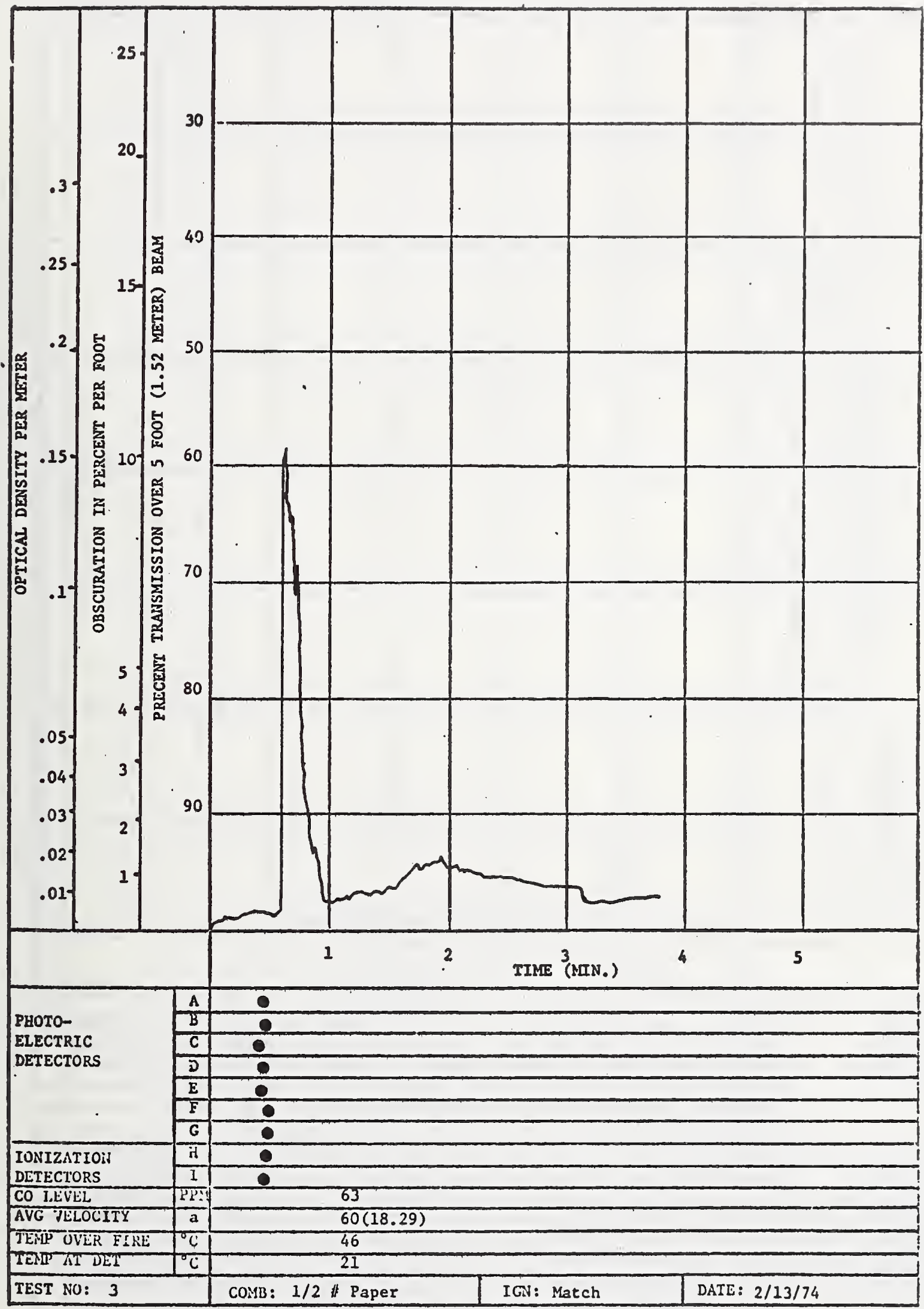

a. VELOCITY LiN FLET TERR MIN (IRETERS PLR NIN)

Figure 3. Results of fire test No. 3. 


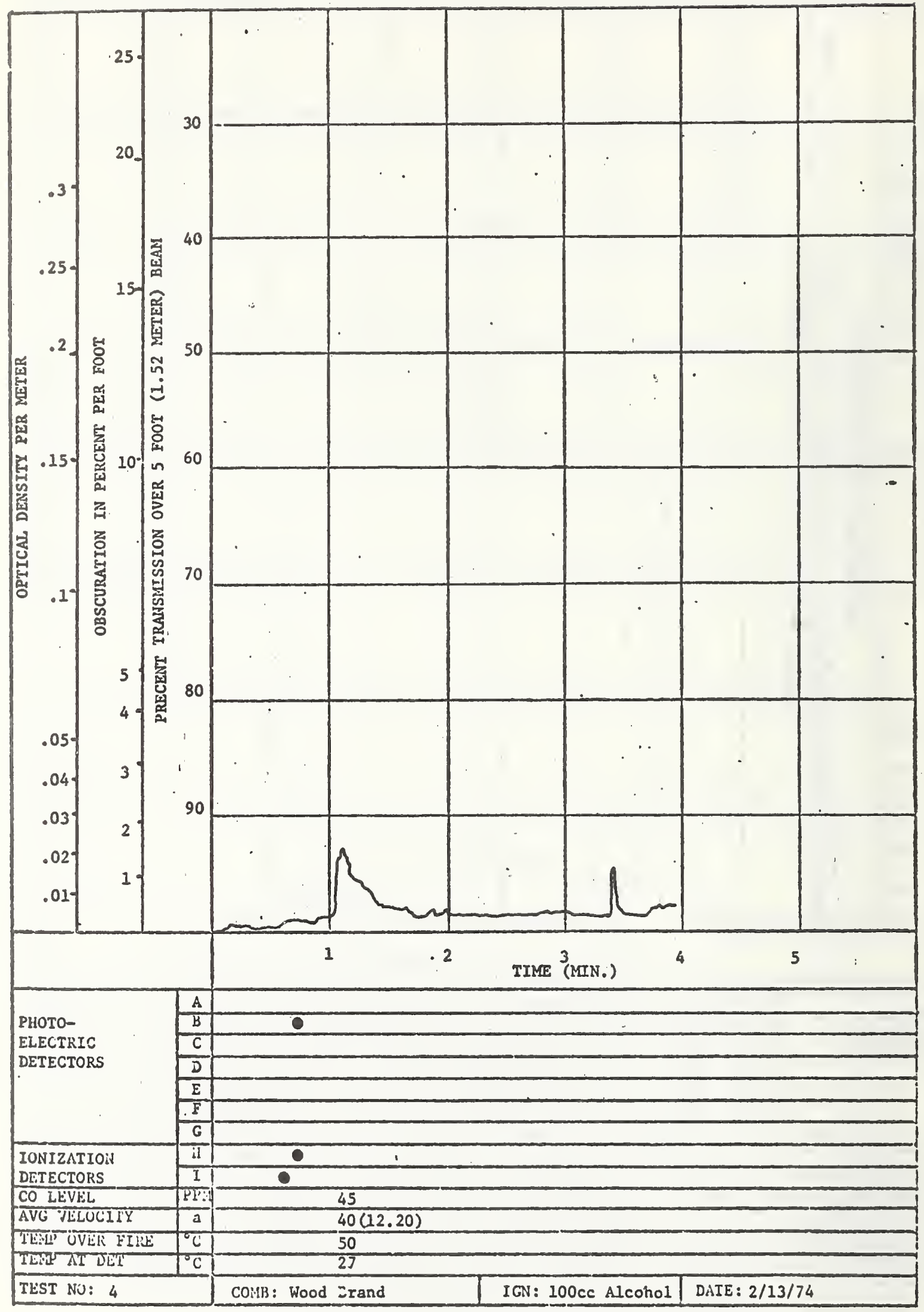

a. VET OCTTY IA FLET PER HII (iLTERS PER MII)

Flgure 4. Results of fire test No. 4. 


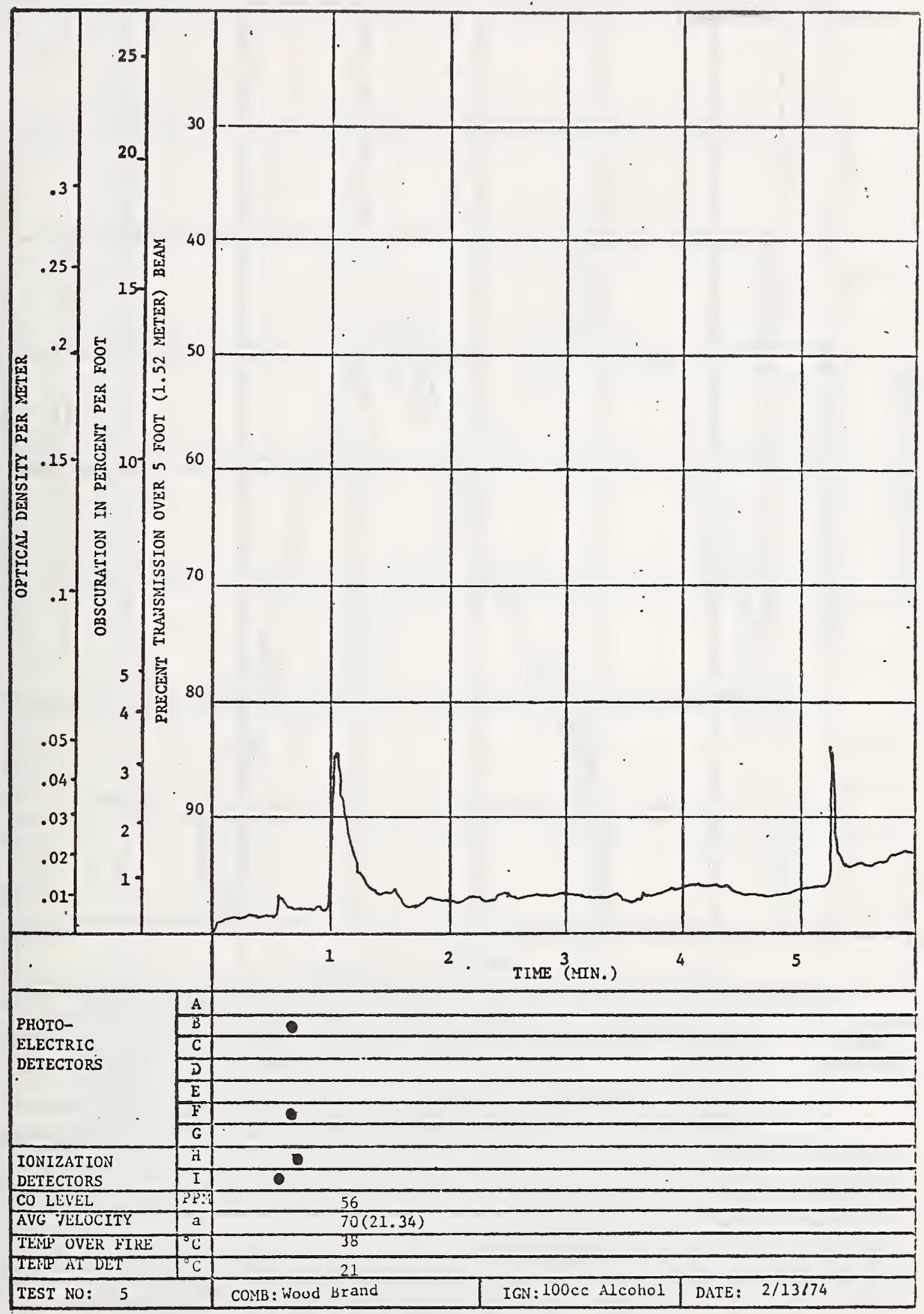

a. VELOCITY IN FLET PER MIN (IETERS PER MIN)

Figure 5. Results of fire test No. 5. 


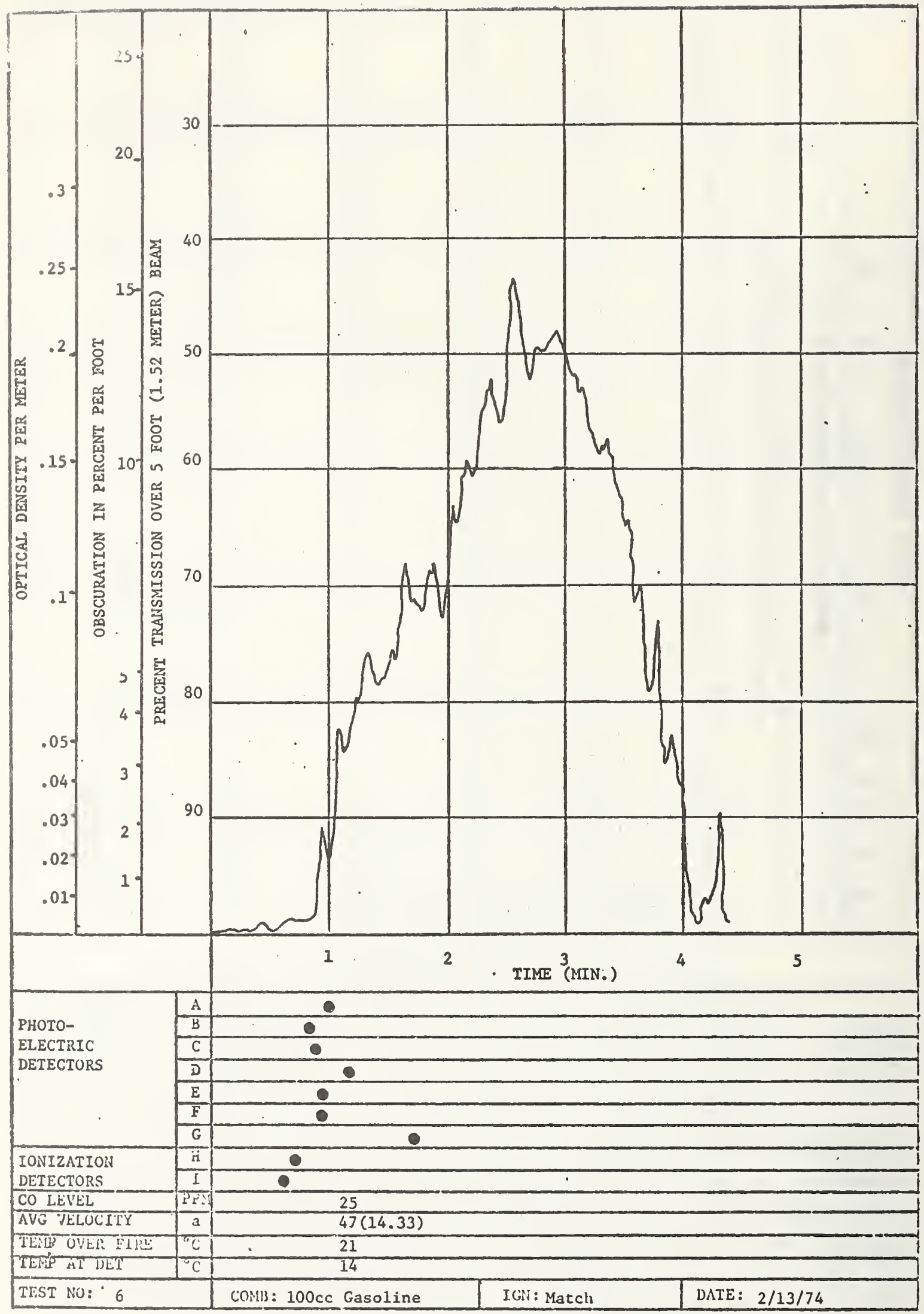

a. VELOCITY IN FLET PER MII (IITTEIS PER RIII)

Figure 6. Results of fire test No. 6. 


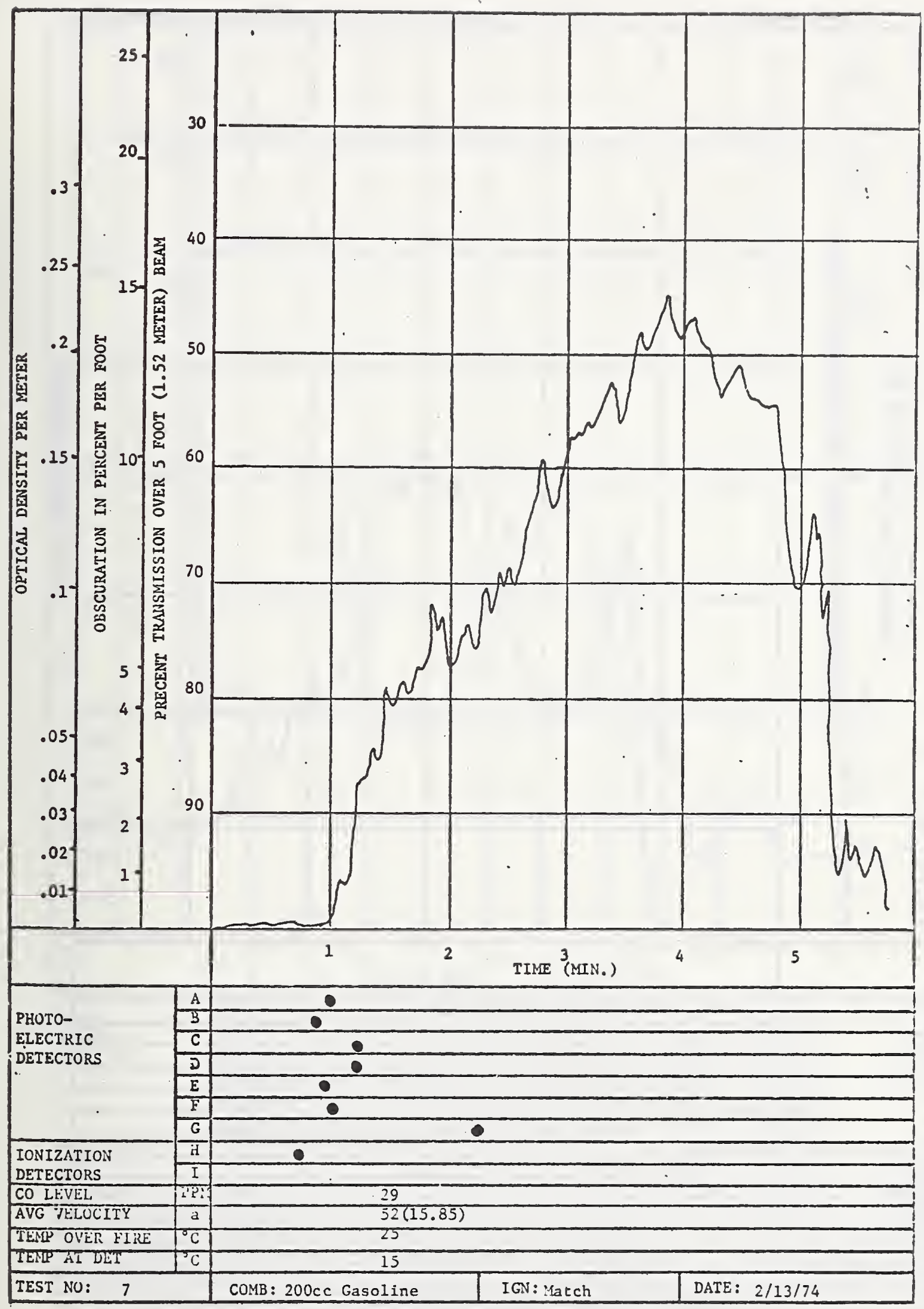

a. VELOCITY IN FEET PER MIN (METERS PER MIN)

Figure 7. Results of fire test No. 7. 


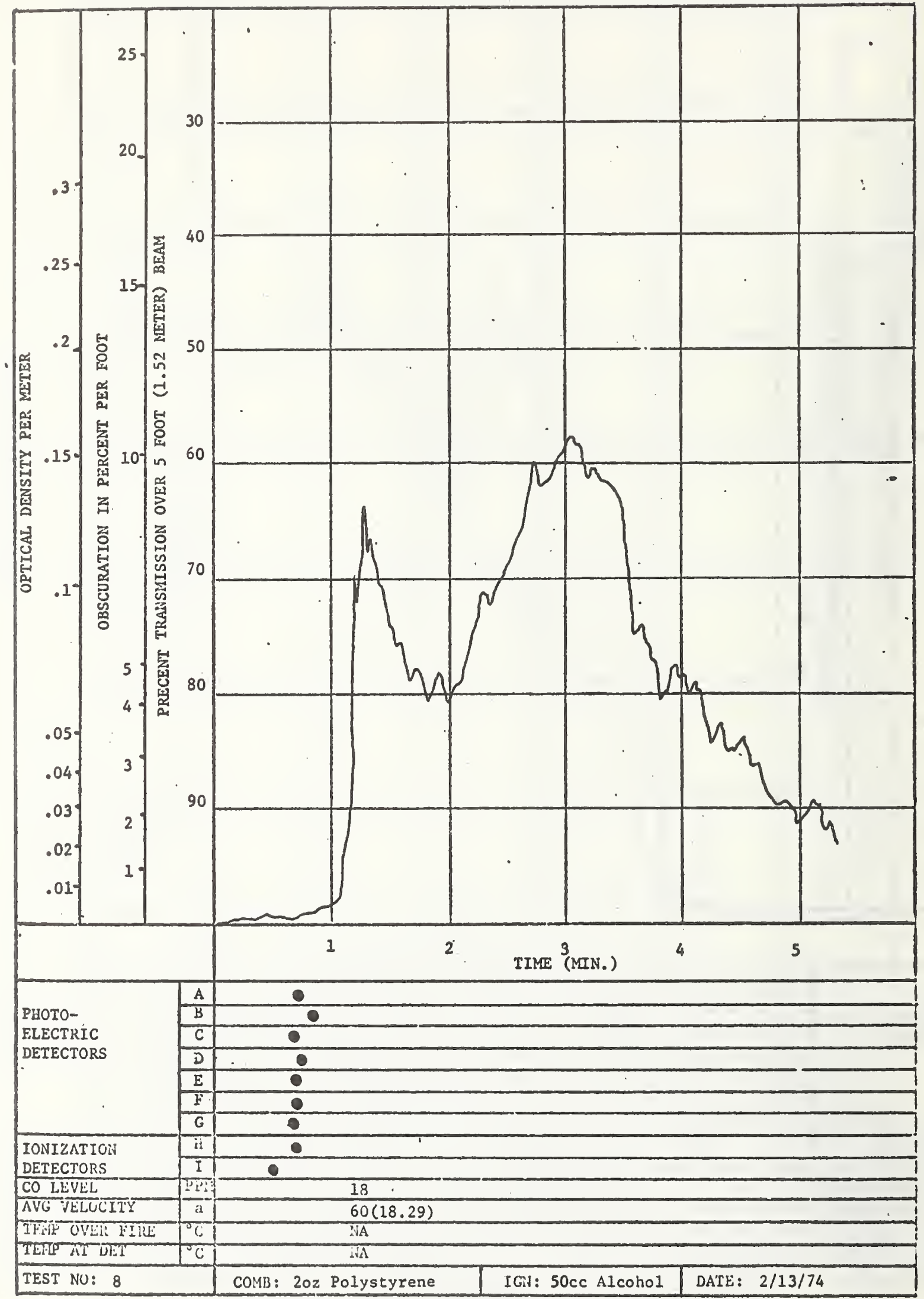

a. VELOCITY II FILLT TER MII (:RTERS PER NIN)

Figure 8. Results of fire test No. 8. 


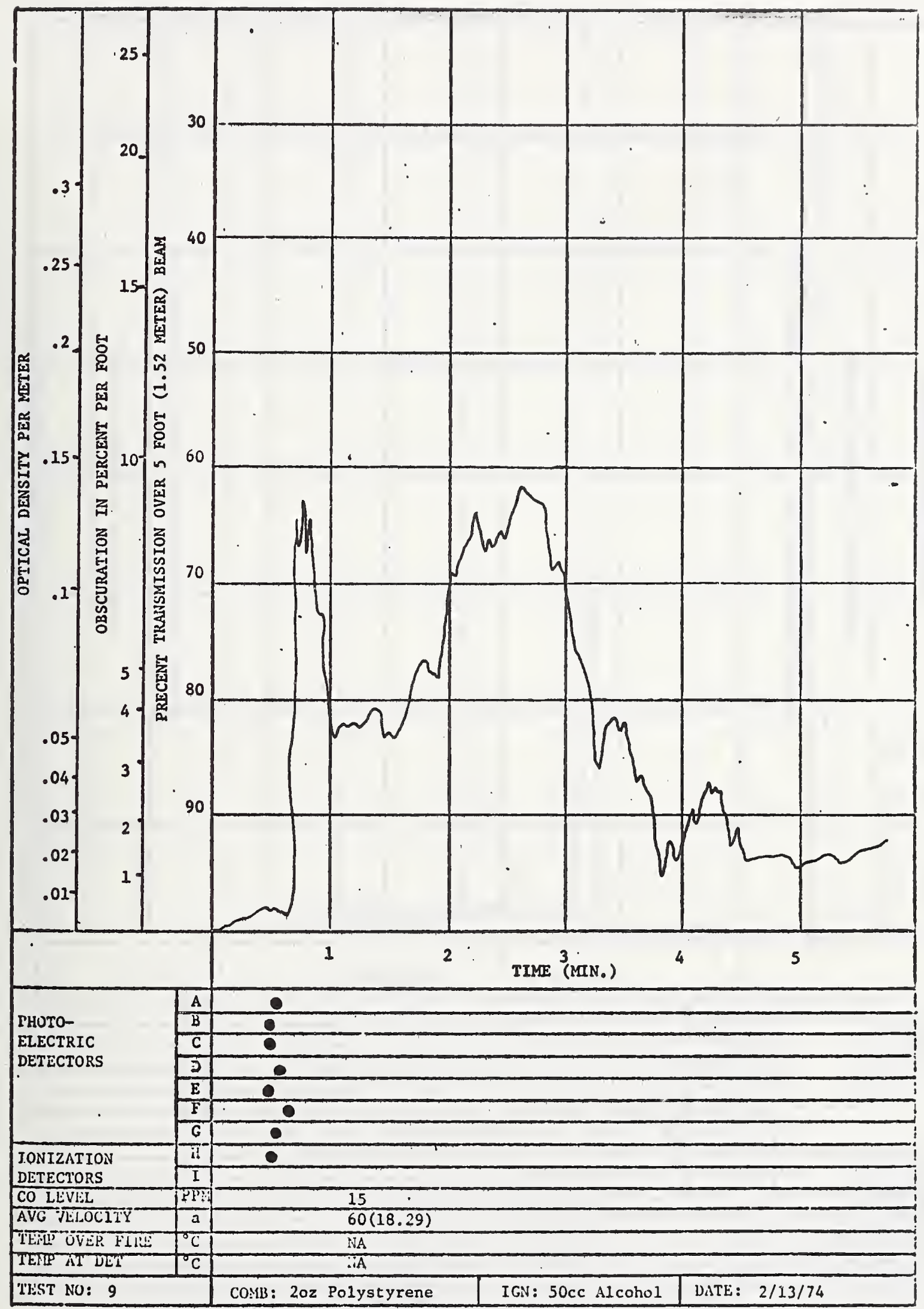

a. VELOCITY IN FLET PER MIN (ID:TERS PER MIN)

Figure 9. Results of fire test No. 9. 


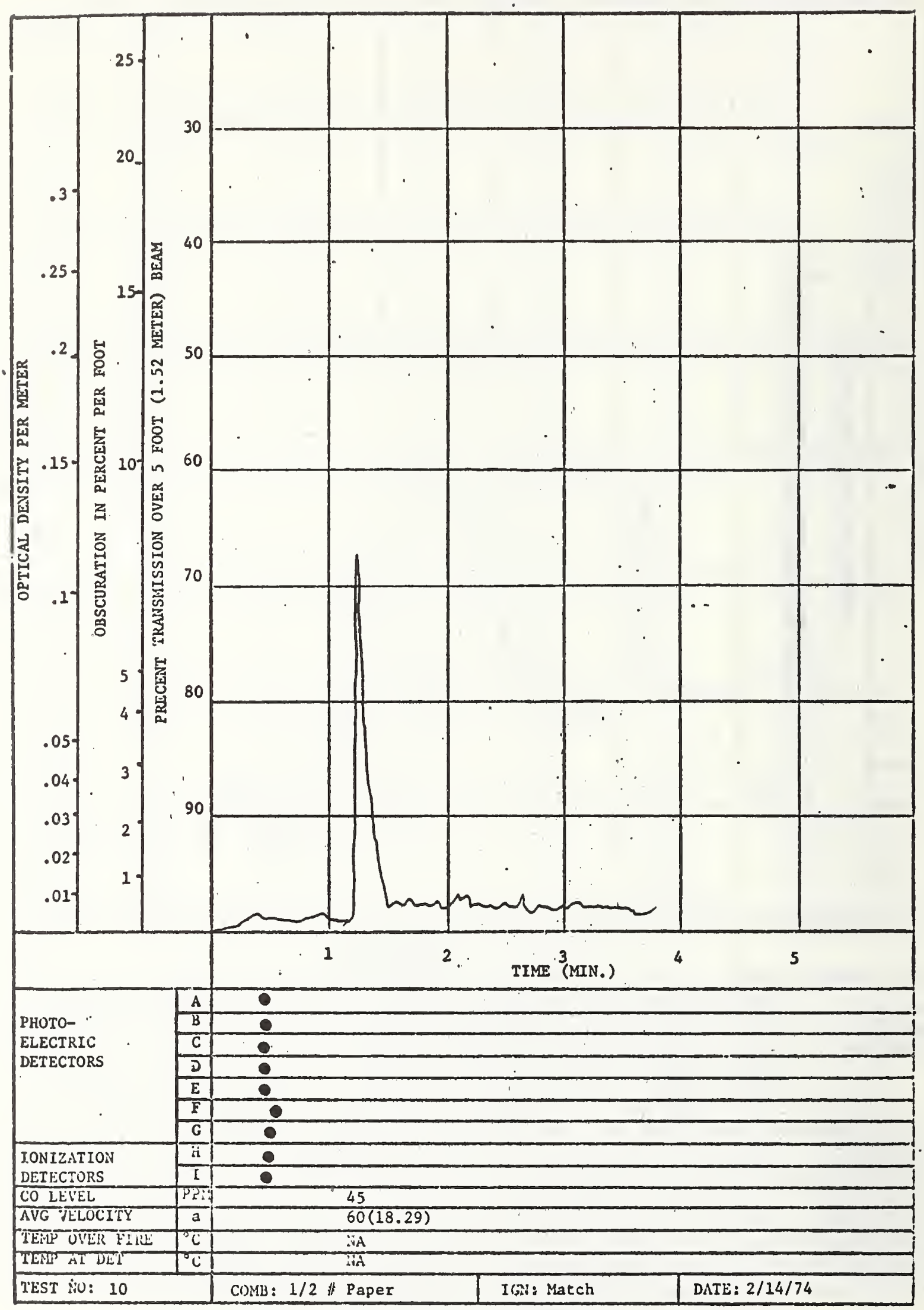

a. VLTOCITY IIN FEET PER MII (ILTERS PER MIN)

F1gure 10. Results of fire test No. 10. 


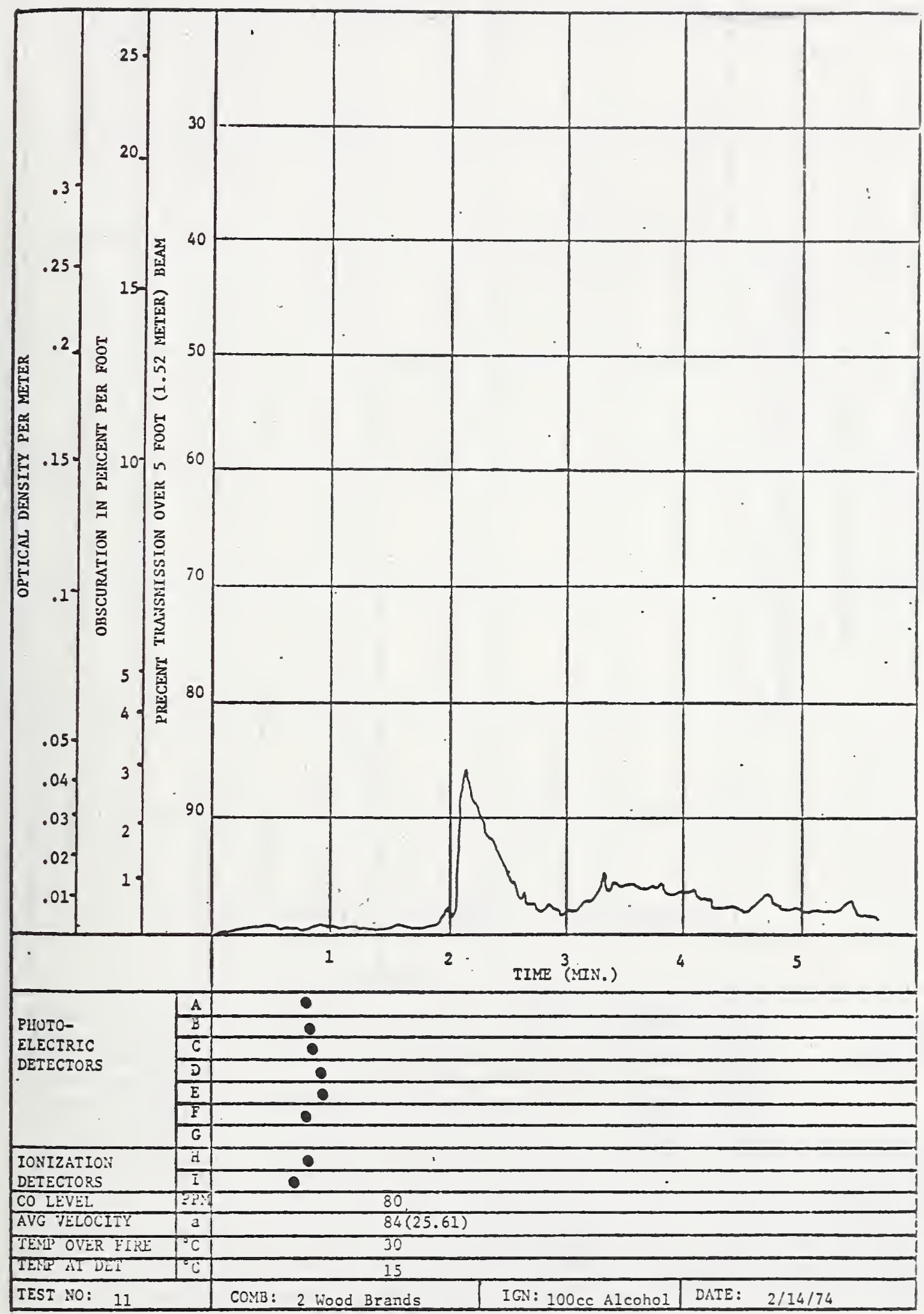

a. VELOCITY IN FEET PER MIN (METERS PER MTN)

F1gure 11. Results of fire test No. 11. 


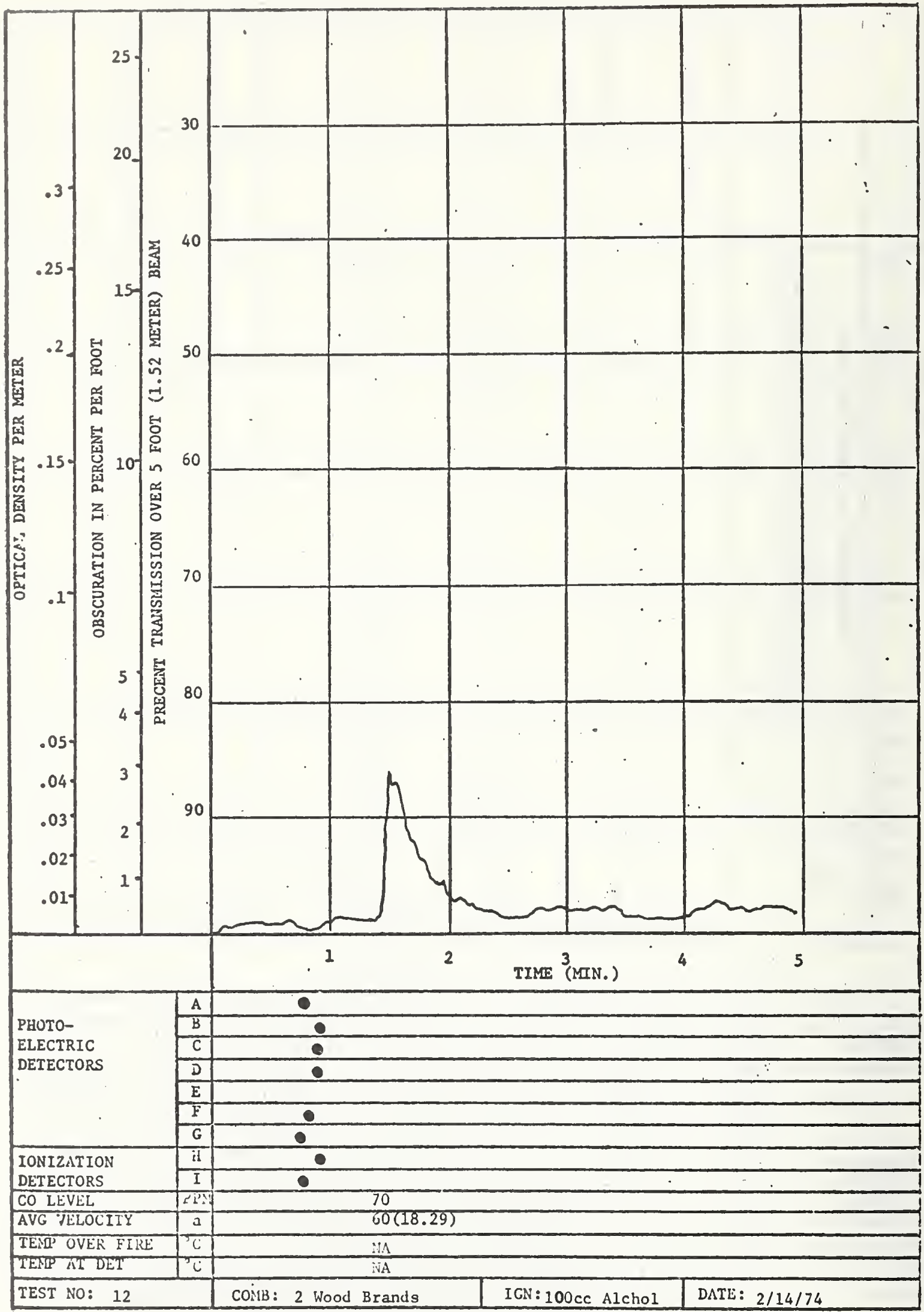

a. VELOCITY IN FEET PER MIN (AETERS PER MIN)

Figure 12. Results of fire test No. 12. 


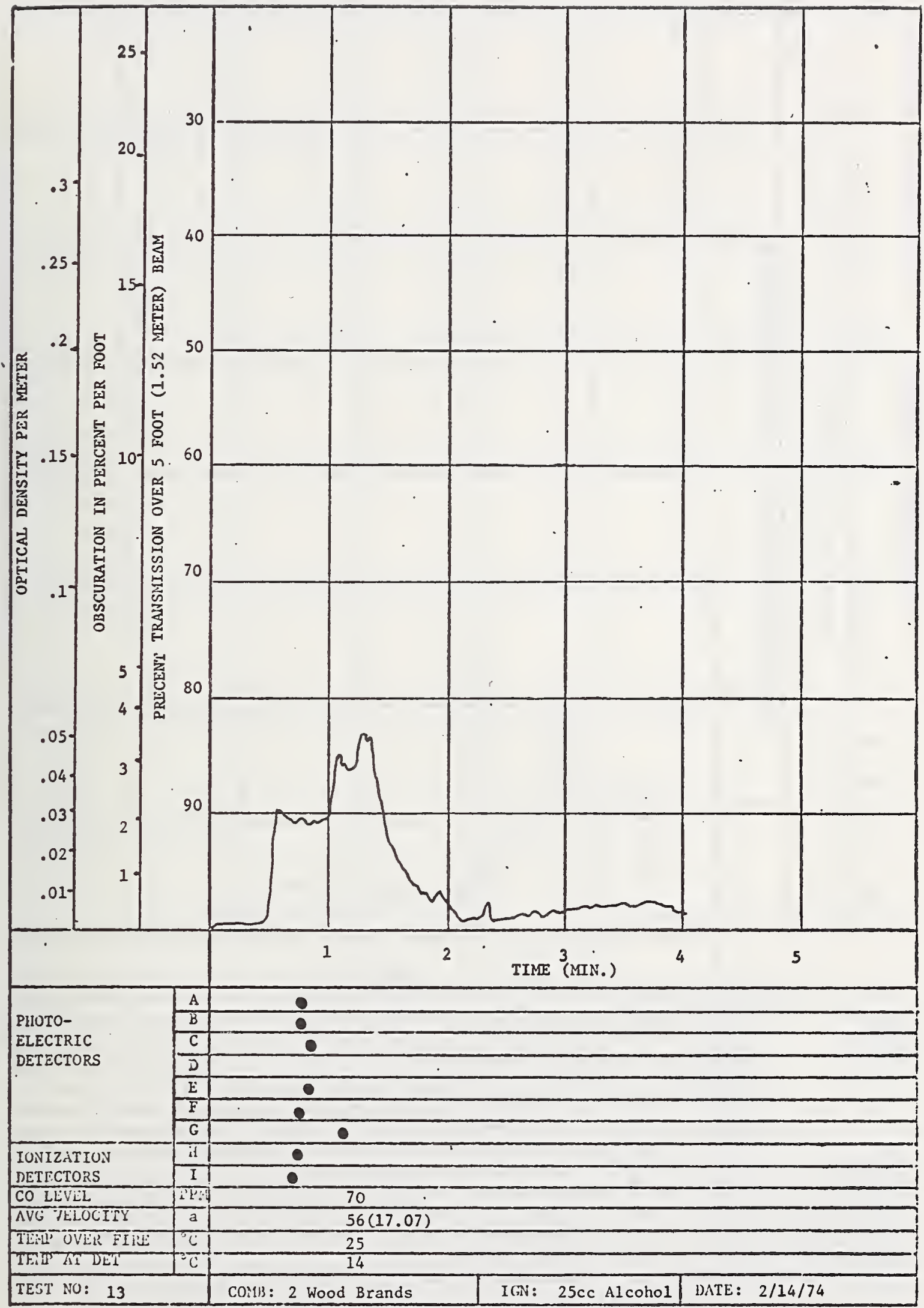

a. VELOCTTY IN FEET PLR MII (IRTERS PER IIN)

Figure 13. Results of fire test No. 13. 


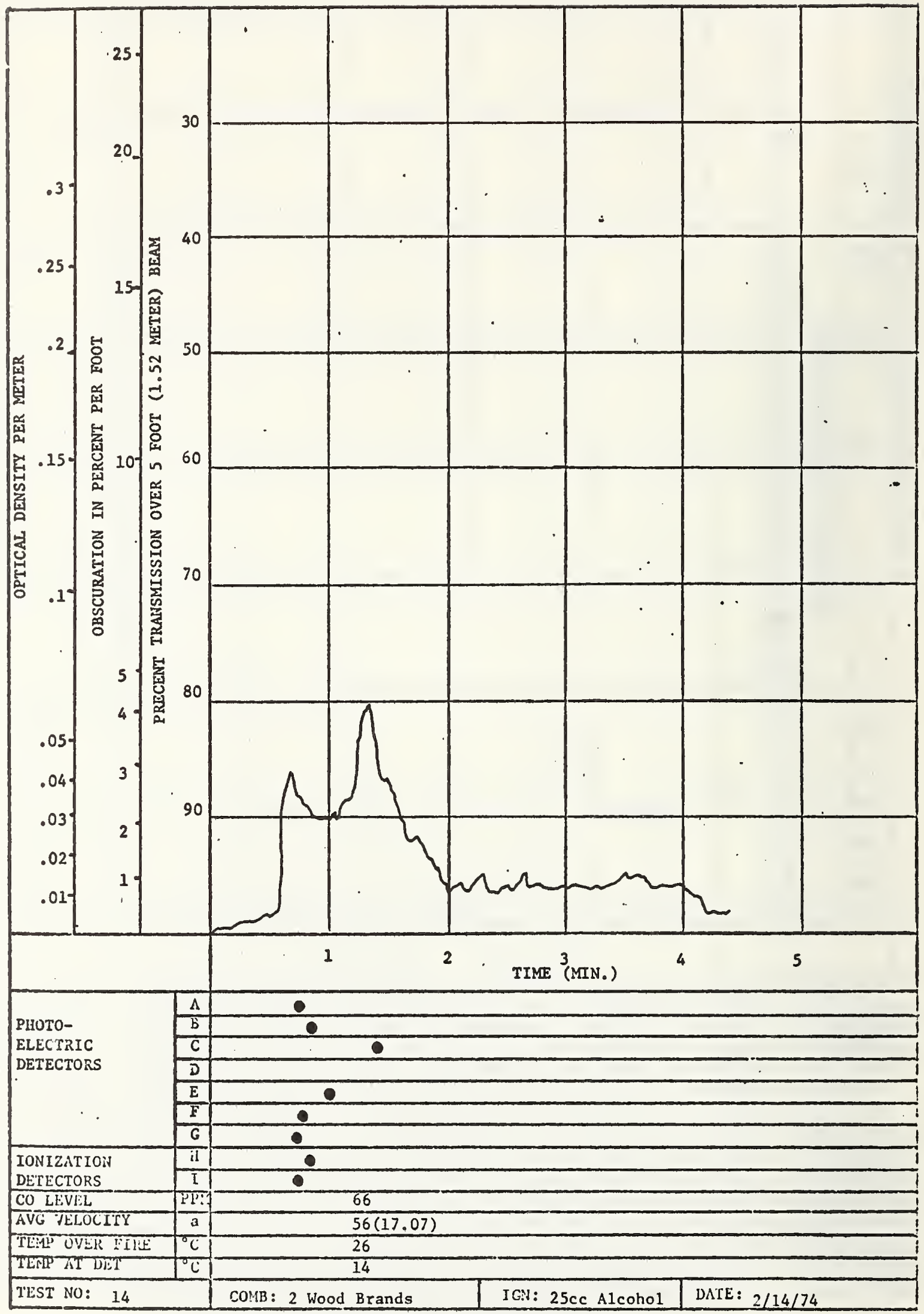

a. VELOCITY tid FEET PEK MII (IELLRS PER MIN)

Figure 14. Results of fire test No. 14. 


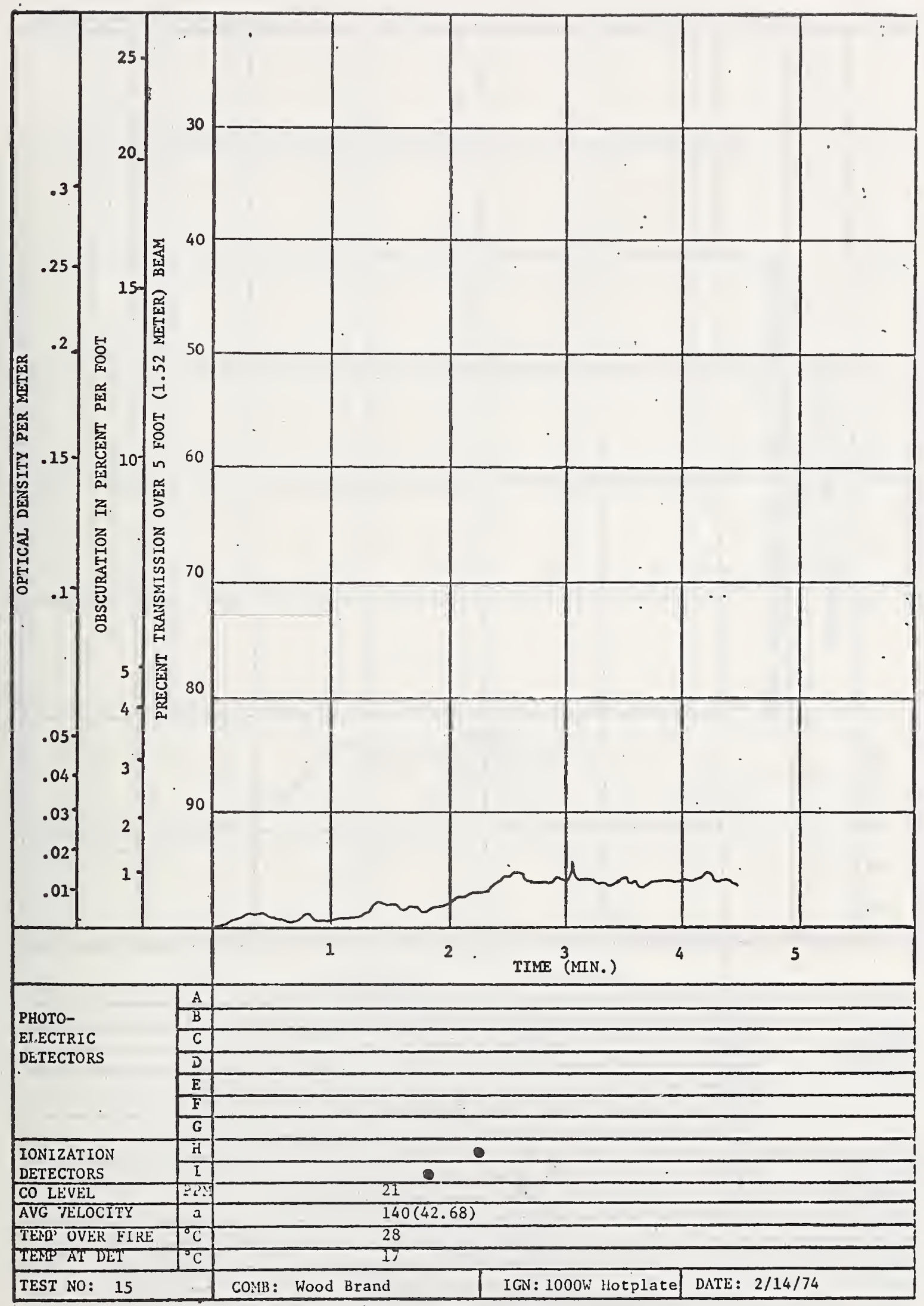

a. VELOCITY IN FEET PER MIN (IETERS PER MIN)

Figure 15. Results of fire test No. 15. 


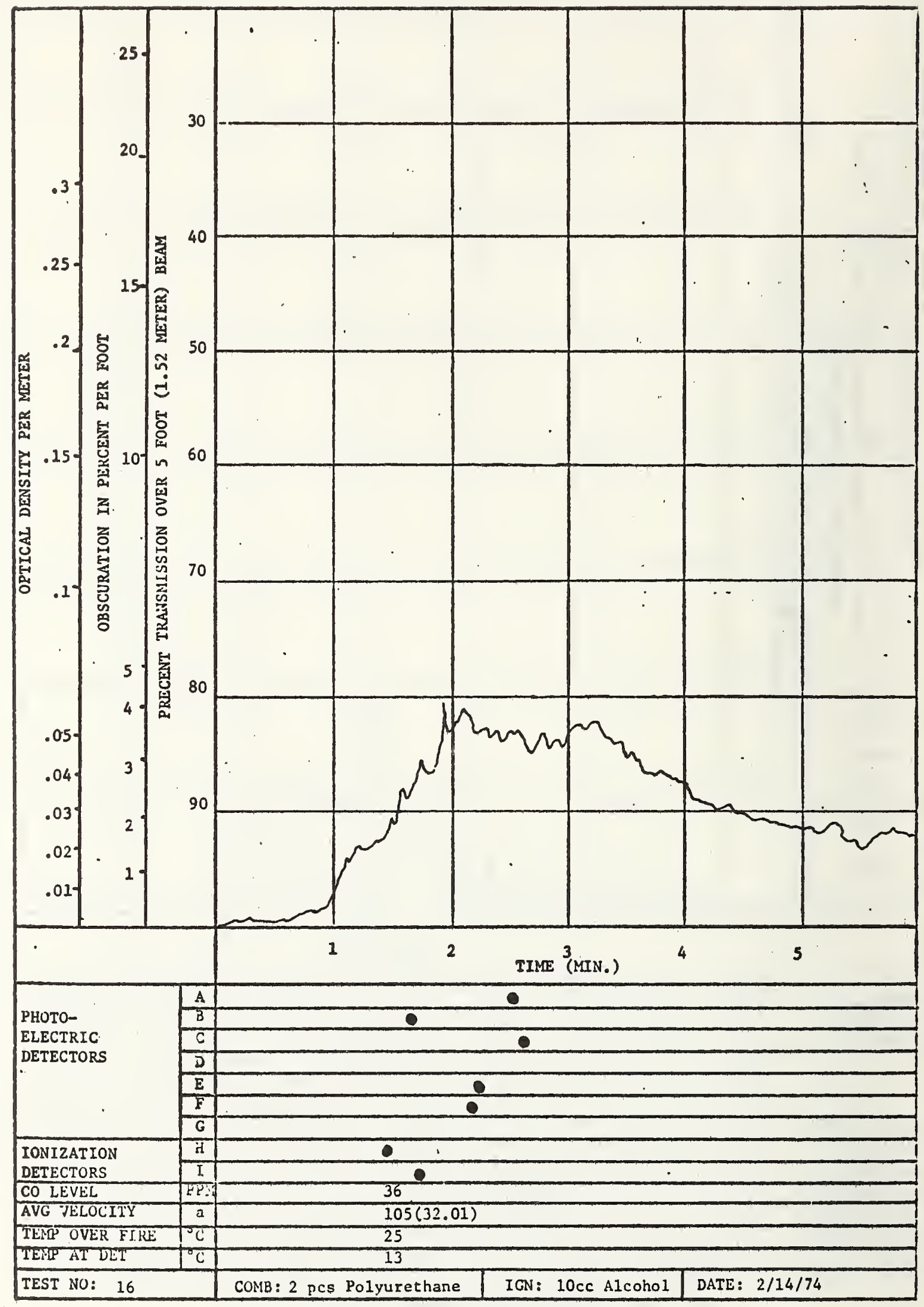

a. VELOCITY IN FEET PER MIN (METERS PER MIN)

Figure 16. Results of fire test No. 16. 


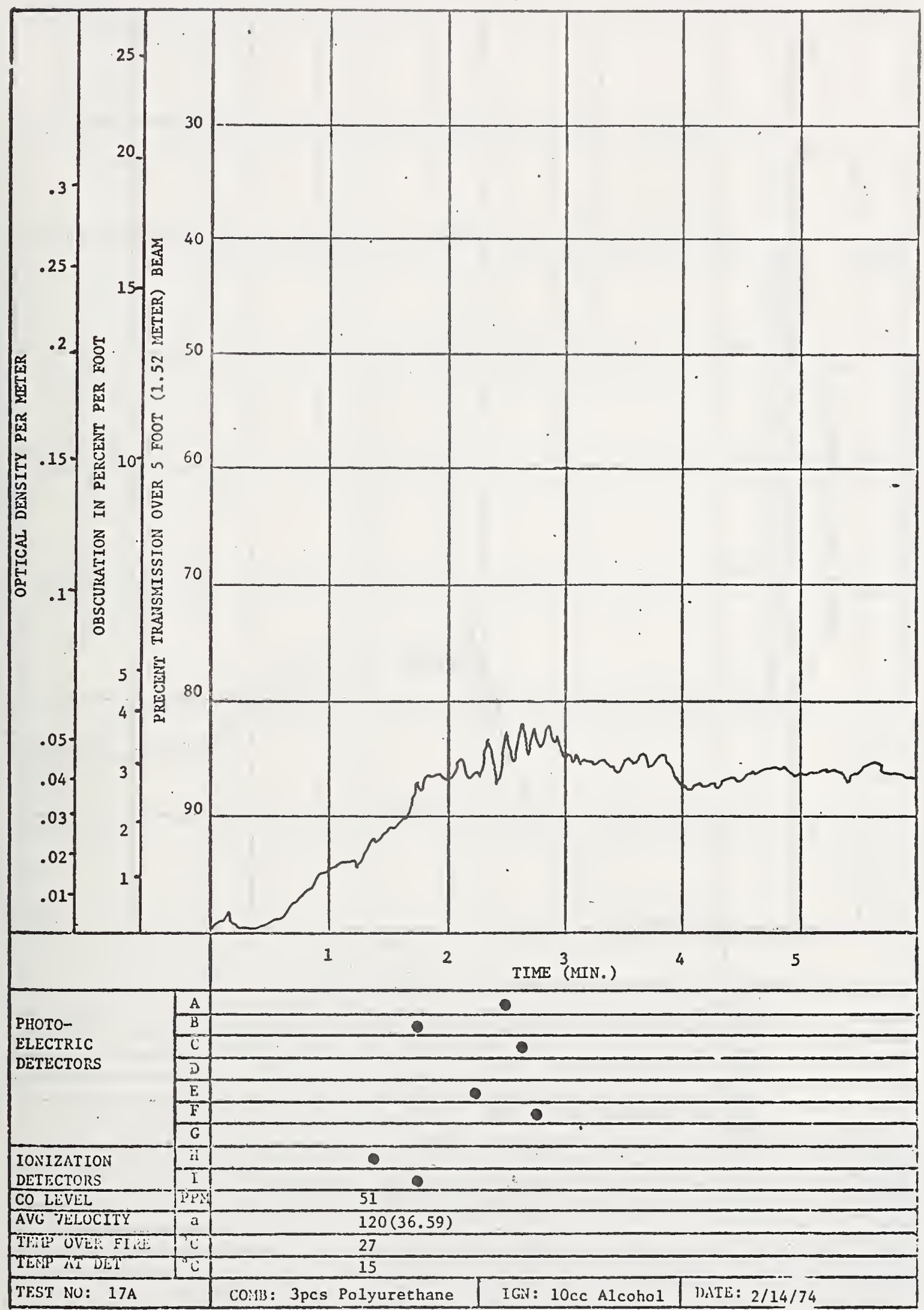

a. VELOCITY Iis TLITT PER MIA (IETERS PLR MII)

Figure 17. Results of fire test No. 17a. 


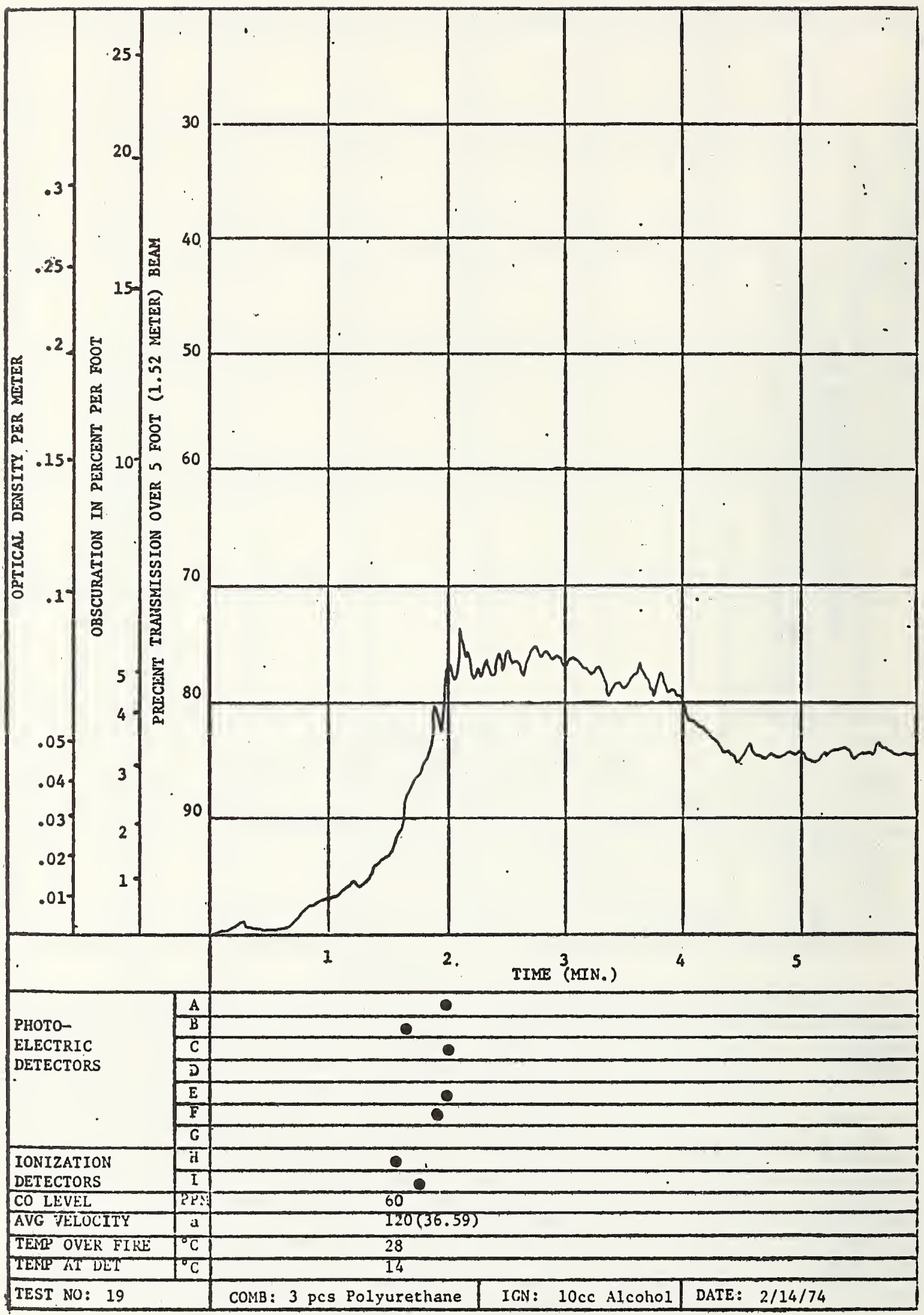

a. VELOCITY IN FLET PER MIN (METERS PER MIN)

Figure 18. Results of fire test No. 19. 


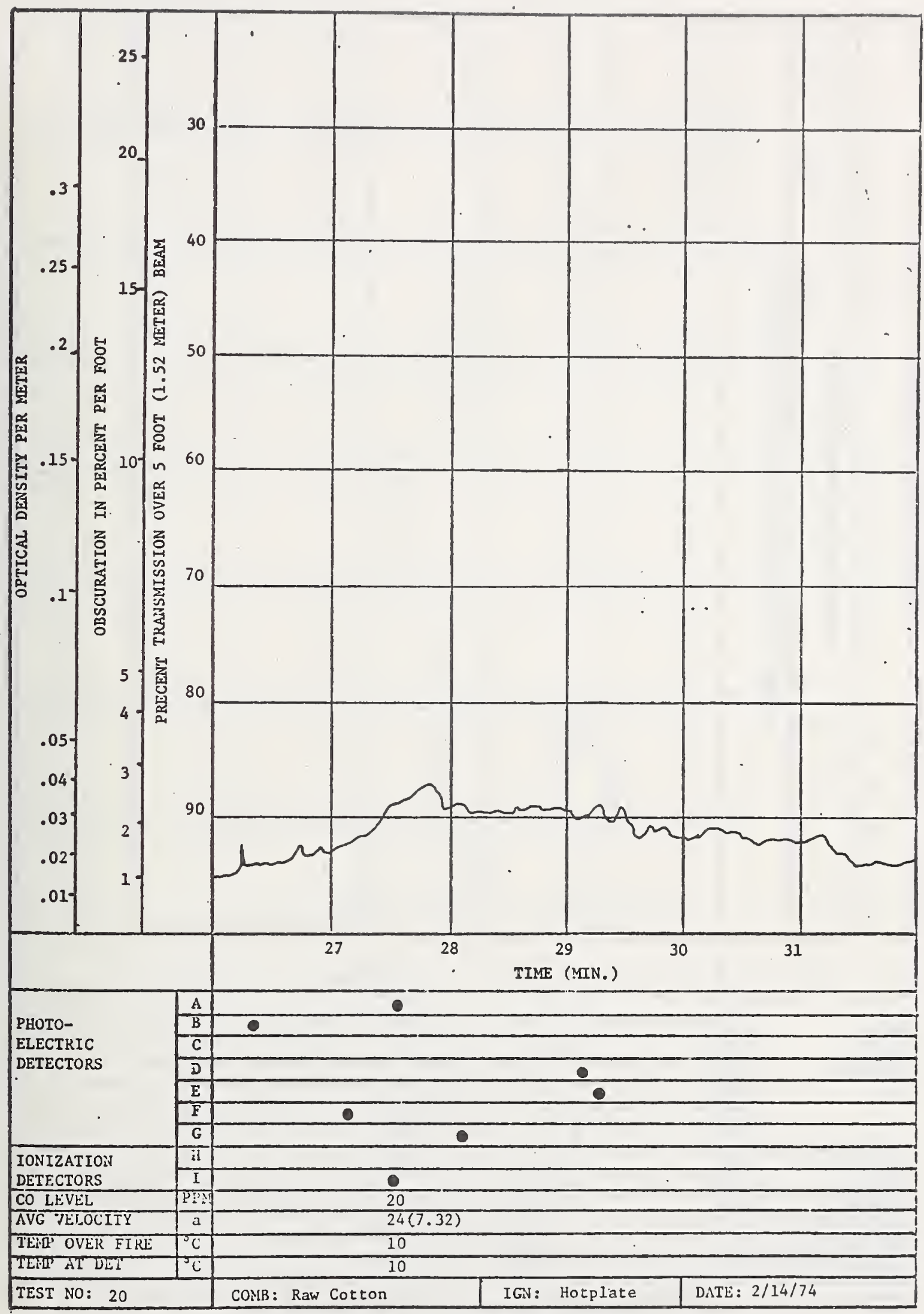

a. VELOCITY IN FEET PER MIN (METERS PER MIN)

Figure 19. Results of fire test No. 20. 


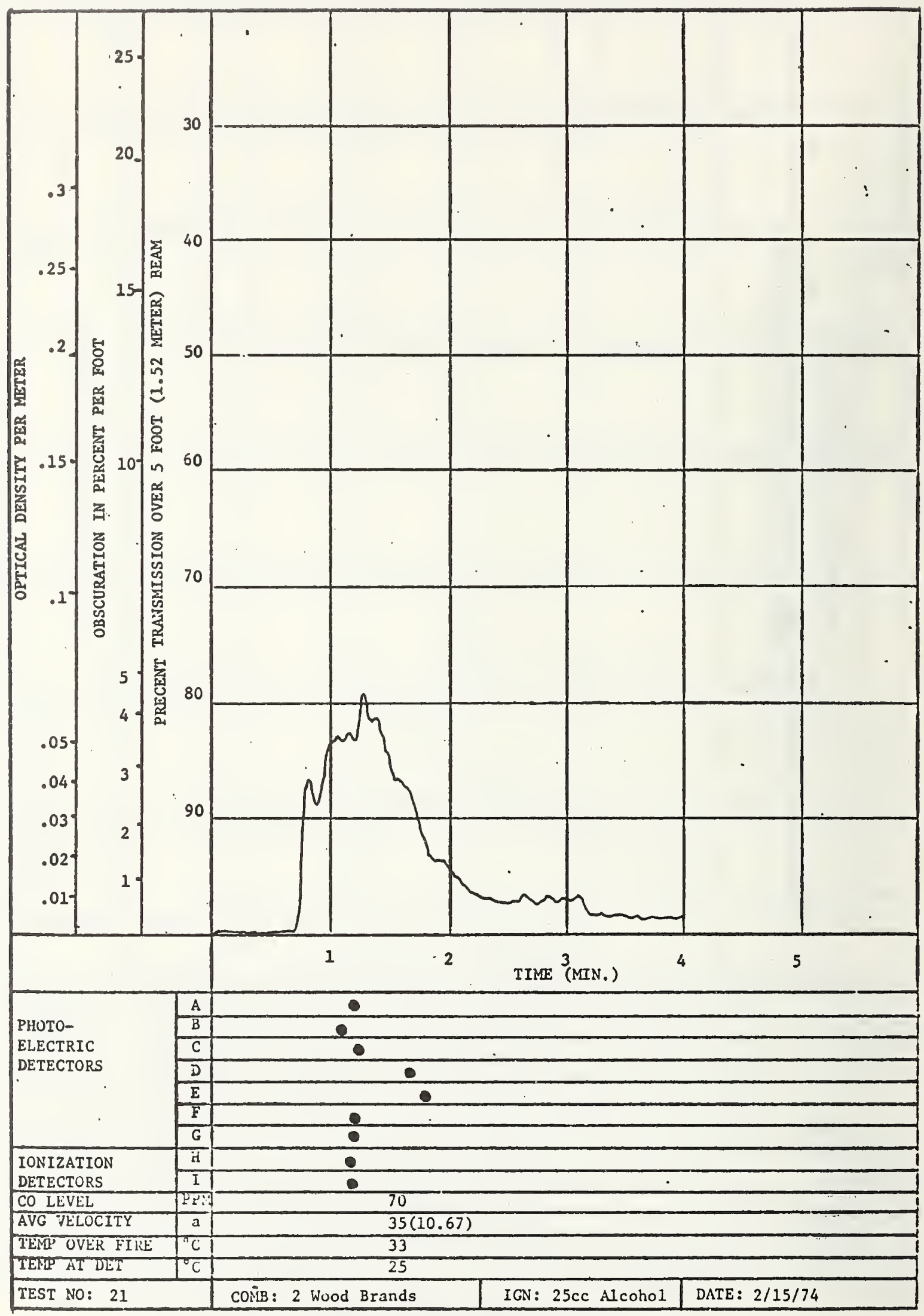

a. VELOCITY IN FEET PER MIN (RETERS PER MIN)

Figure 20. Results of fire test No. 21. 


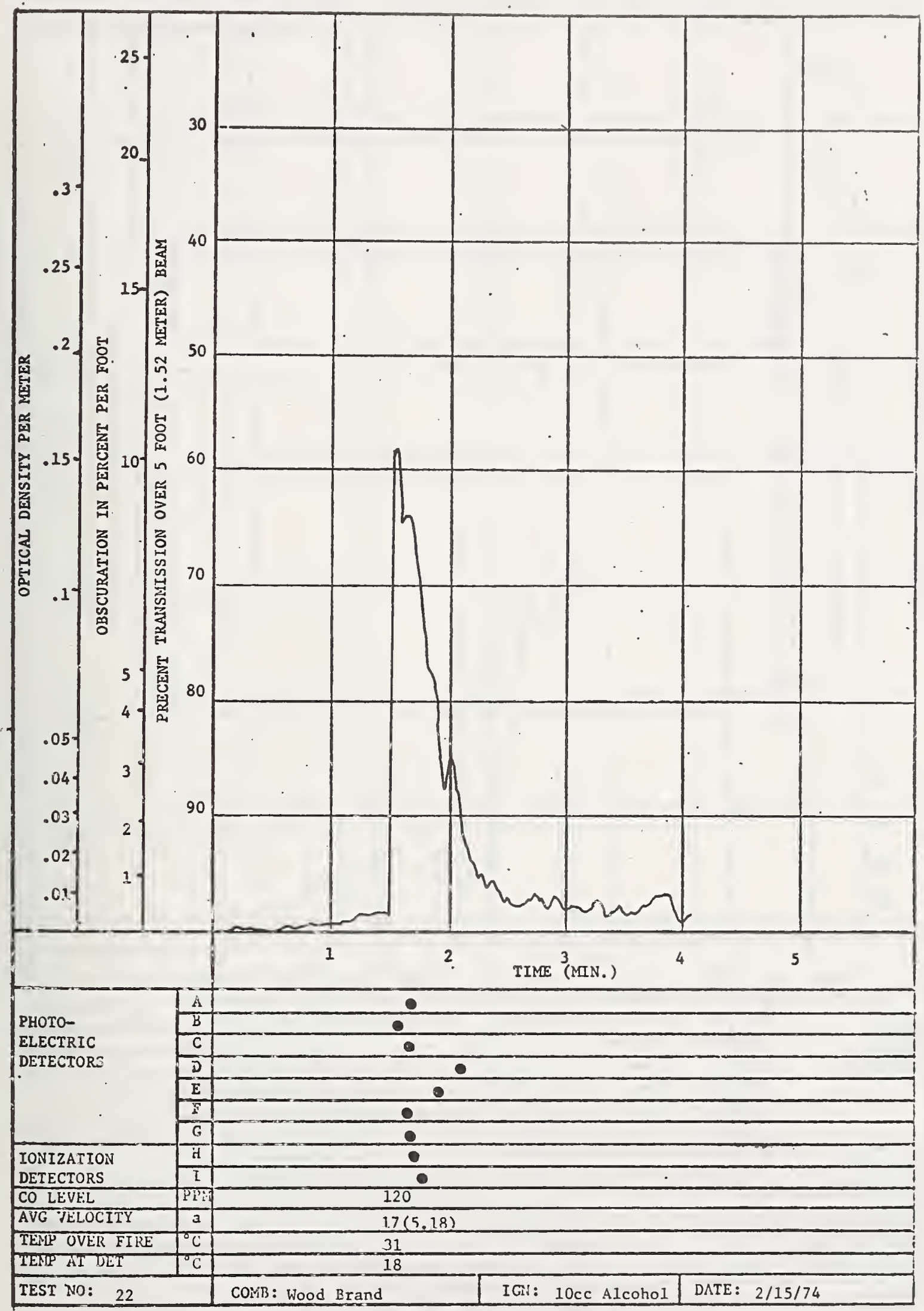

a. VELOCITY IN FEET PER MIN (METERS PER MIN)

Figure 21. Results of fire test No. 22. 


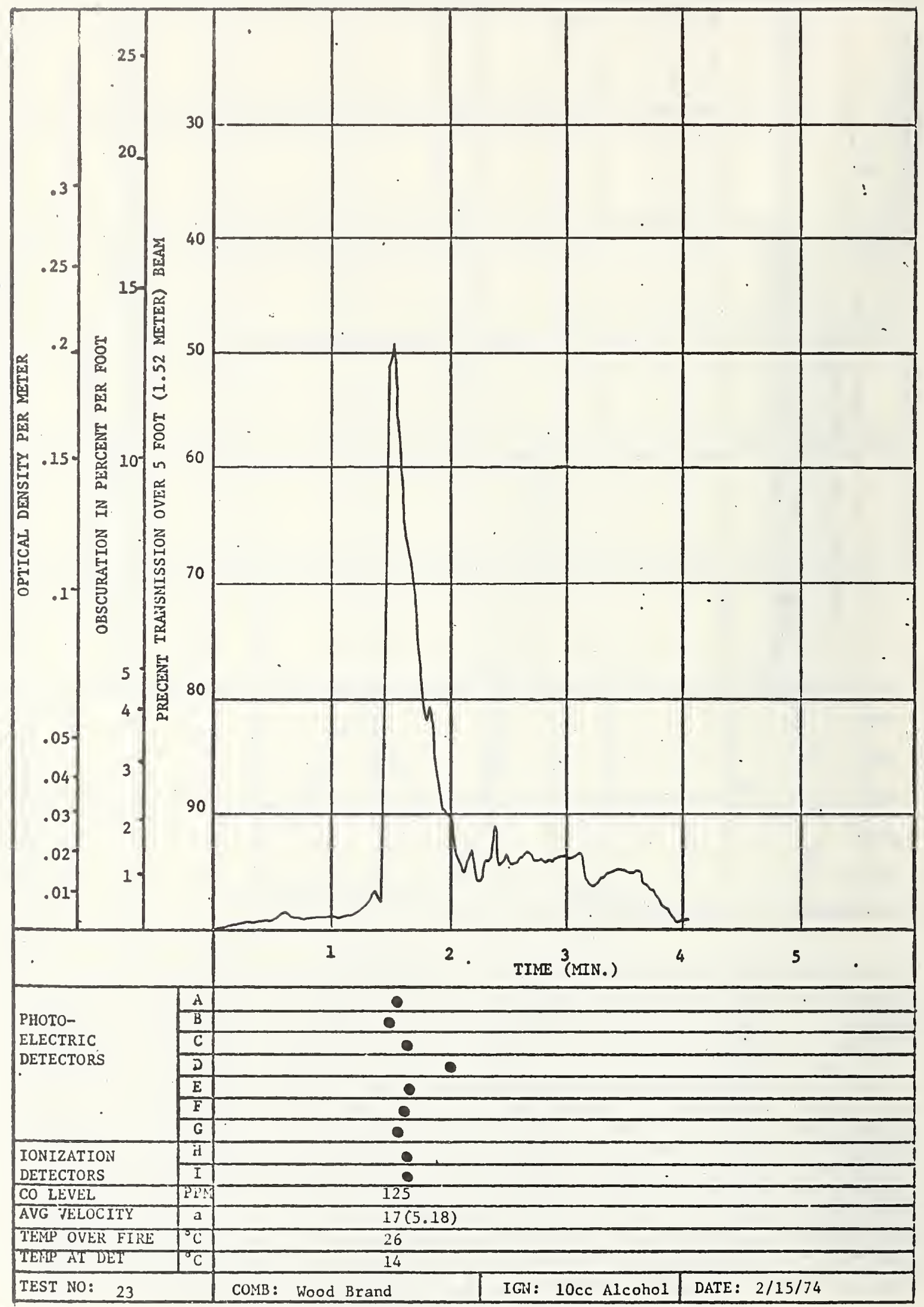

a. VELOCITY IN FEET PER MIN (LETERS PER MIN)

Figure 22. Results of fire test No. 23. 


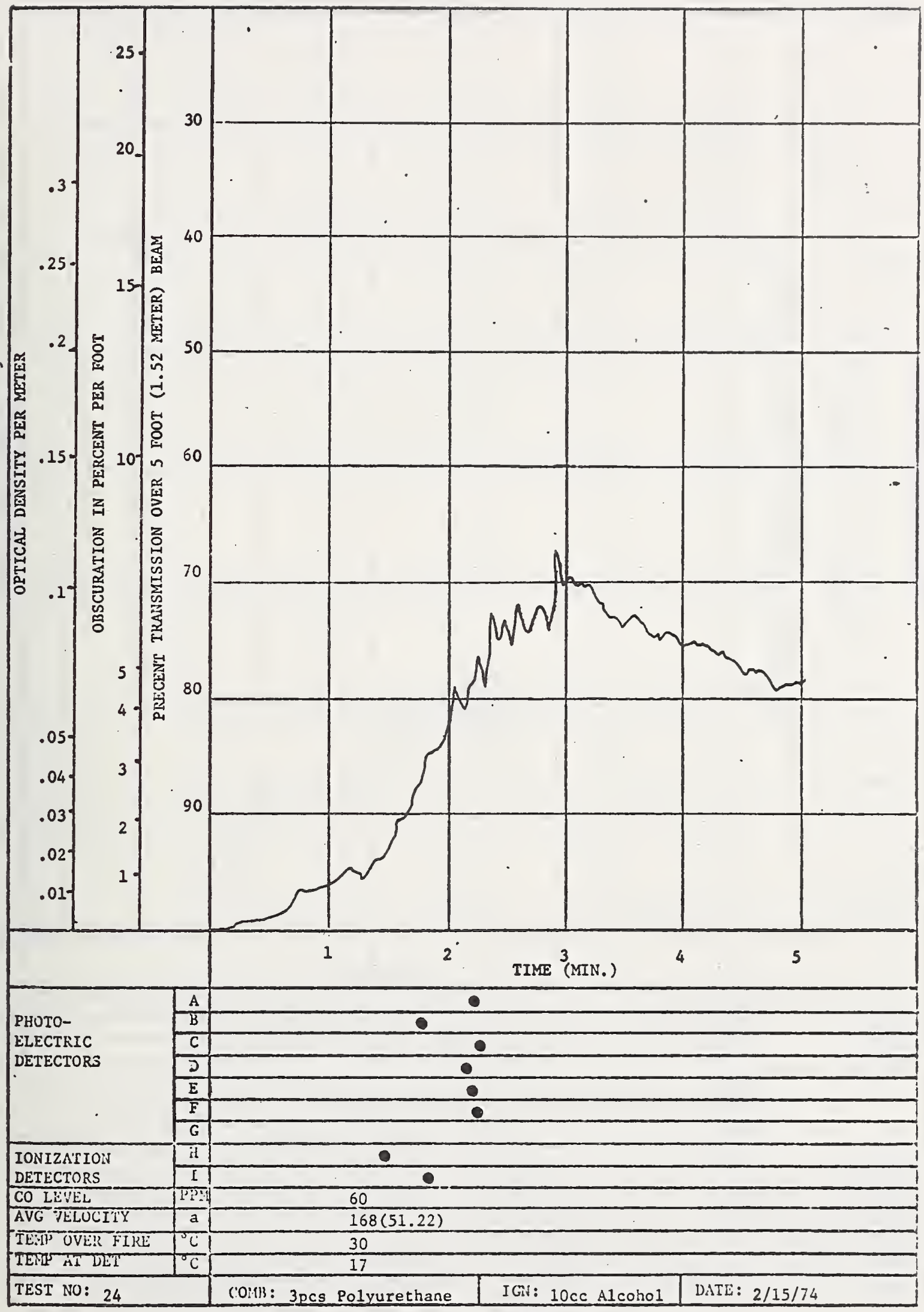

a. VELOCITY III FELT PER NIT (:OTERS PIER MIN)

F1gure 23. Results of fire test No. 24. 


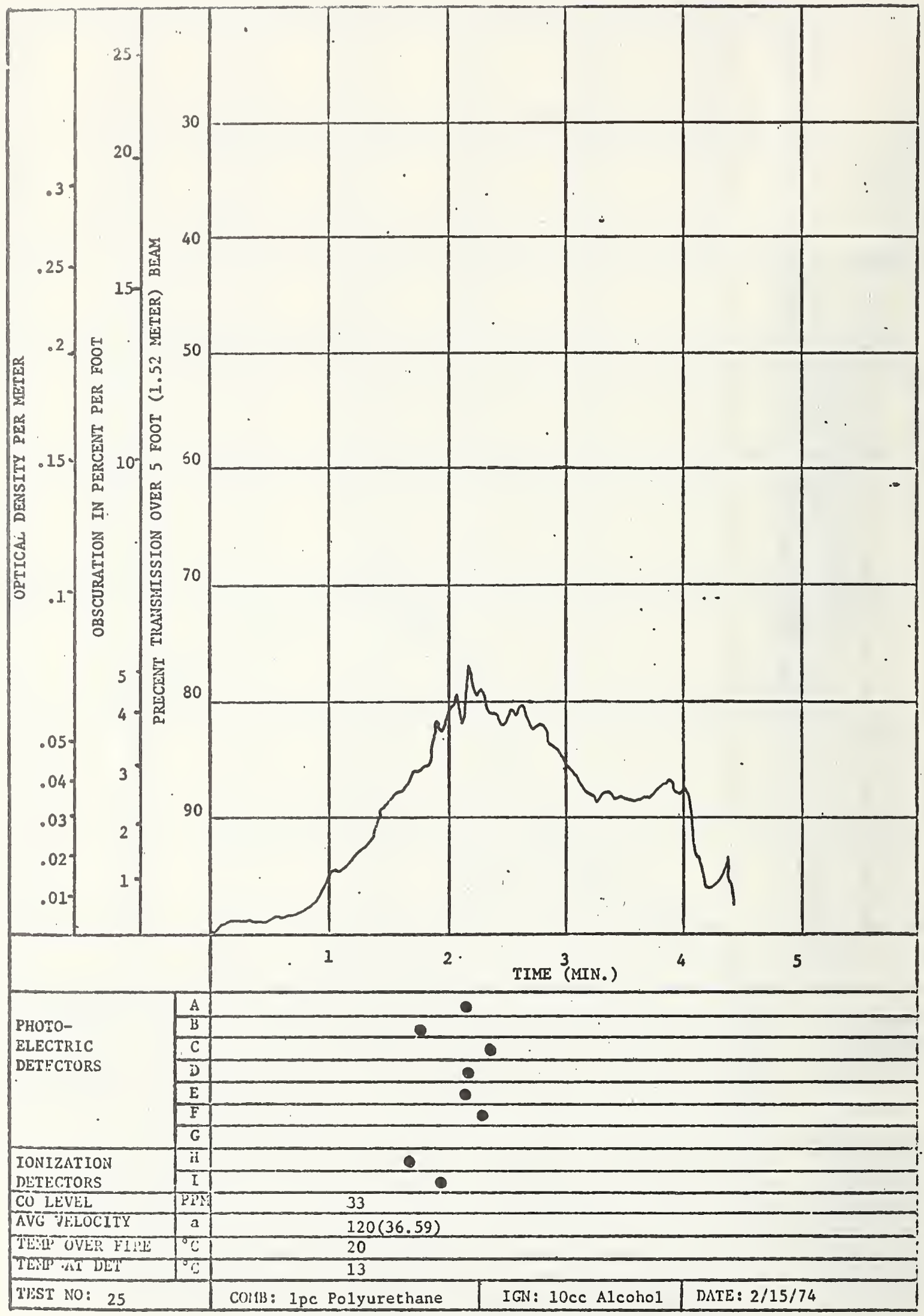

a. VELOCITY IH FELT PER MIH (:AZTERS PER. MIN)

Figure 24. Results of fire test No. 25. 


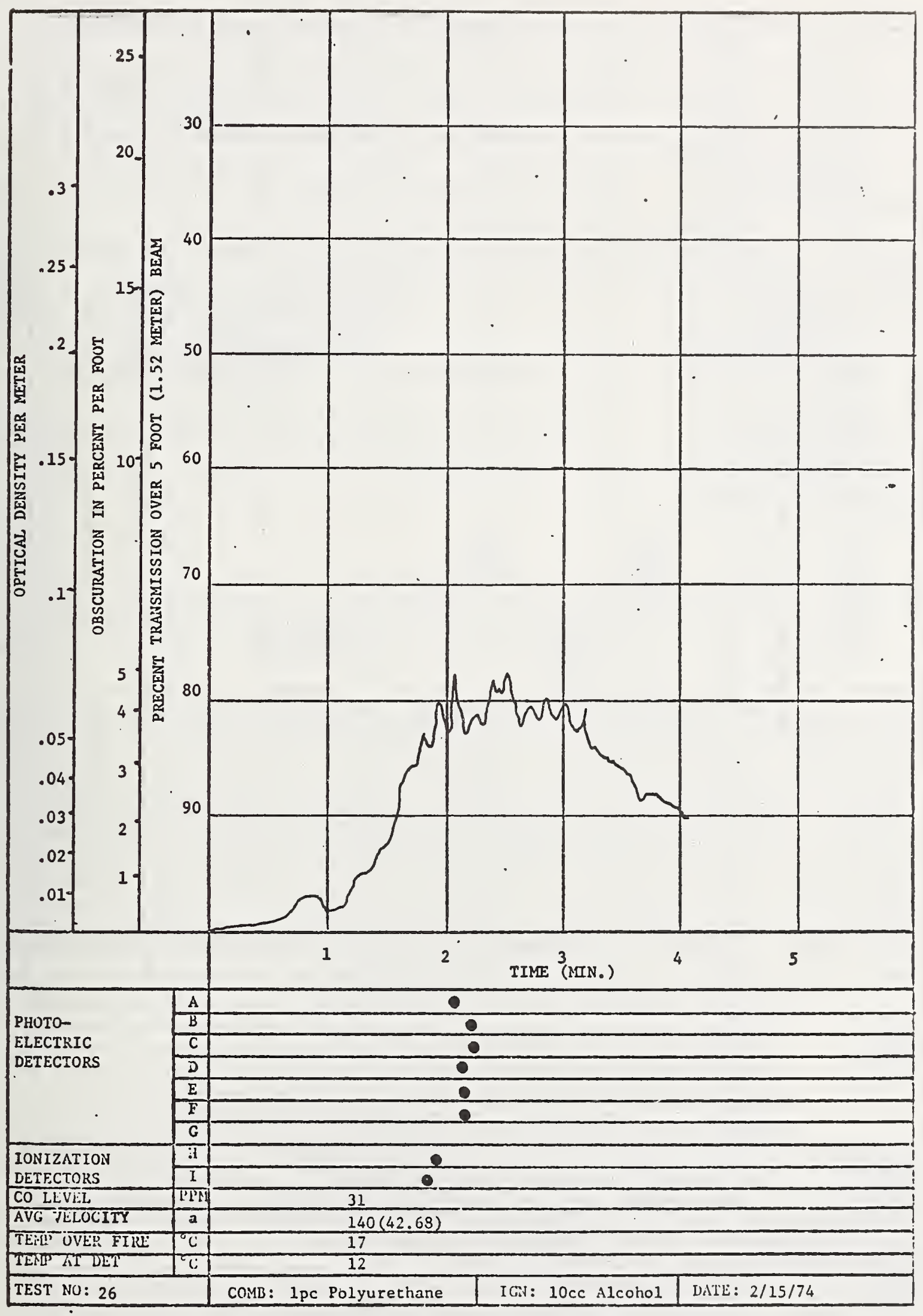

a. VELOCIYY I.S FELT PER NIU (IITERS PER UIN)

Figure 25. Results of fire test No. 26. 


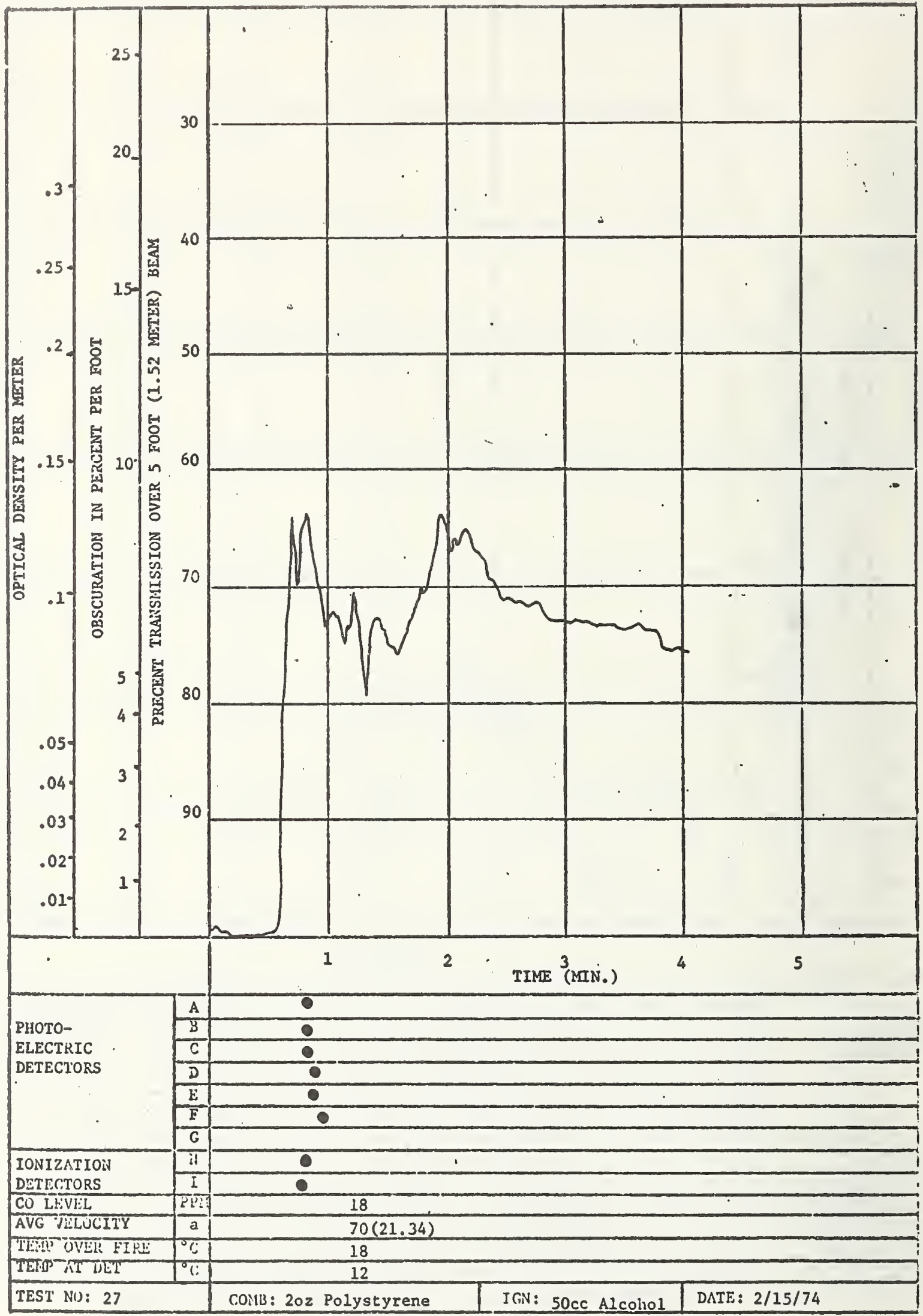

a. VRLOCITY IN FLET PER MIN (IRTERS PER NLW)

Figure 26. Results of fire test No. 27. 
NBS-114A (REV. 7.73)

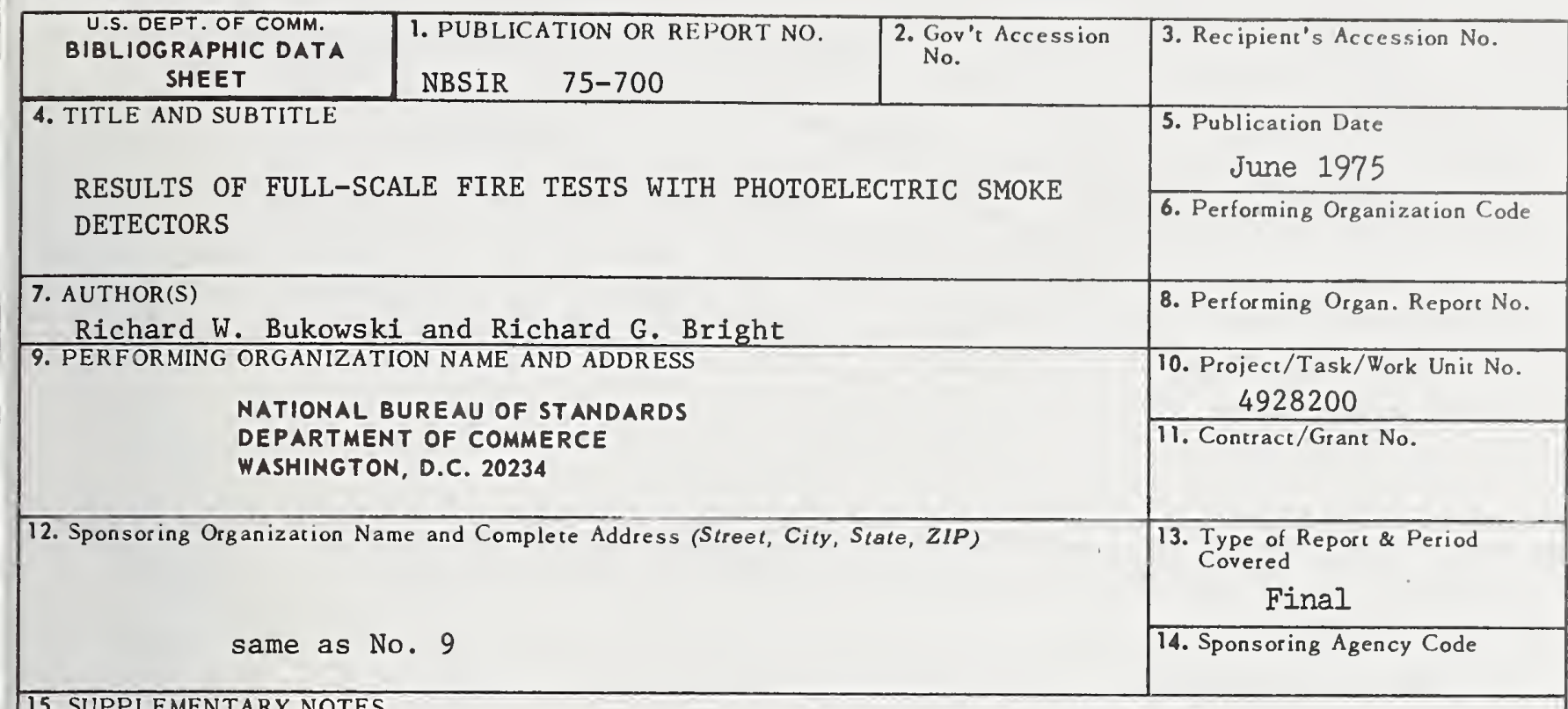

15. SUPPLEMENTARY NOTES

16. ABSTRACT (A 200-word or less factual summary of most significant in formation. If document includes a significant bibliography or literature survey, mention it here.)

In February 1974, a series of full-scale fire tests were conducted to determine whether photoelectric-type smoke detectors could respond to the same types of fires used to assess the performance of ionization-type smoke detectors. The types of fires employed in the tests are the same as those outlined in Underwriters' Laboratories, Inc., Standard No. 167. In addition to the UL-167 standard fires, fires involving polyurethane (flaming mode) and cotton (smoldering mode) were added to the test series. One detector, utilizing a Taguchi gas sensor (TGS), was included in the test series for evaluation purposes. The test results indicated that the better photoelectric smoke detectors, i.e., those having little obstruction to slow-moving smoke can, in general, detect the same test fires as the ionization chamber smoke detectors in approximately the same time scale. For the smoldering cotton fire, the photoelectric detectors were significantly faster than the ionization chamber detectors. The TGS fire detector was unable to detect most of the test fires.

17. KEY WORDS (six to twelve entries; alphabetical order; capitalize only the first letter of the first key word unless a proper name; separated by semicolons)

Fire detectors; ionization chamber smoke detectors; photoelectric smoke detectors; smoke detectors; Taguchi gas sensors.

\begin{tabular}{|c|c|c|}
\hline $\begin{array}{l}\text { 18. AVAILABILITY }[\mathrm{x} \text { Unlimited } \\
\square \text { For Official Distribution. Do Not Release to NTIS }\end{array}$ & $\begin{array}{l}\text { 19. SECURITY CLASS } \\
\text { (THIS REPURT) } \\
\text { UNCL. ASSIFIED }\end{array}$ & $\begin{array}{l}\text { 21. NO. OF PAGES } \\
50 \\
55\end{array}$ \\
\hline $\begin{array}{l}\square \text { Order From Sup. of Doc., U.S. Government Printing Office } \\
\text { Washington, D.C. } 20402, \text { SD Cat. No.C13 }\end{array}$ & $\begin{array}{l}\text { 20. SECURITY CLASS } \\
\text { (THIS PAGE) }\end{array}$ & 22. Price \\
\hline $\begin{array}{l}\text { X Order From National Technical Information Service (NTIS) } \\
\text { Springfield, Virginia } 22151\end{array}$ & UNCLASSIFIED & $\$ 4.25$ \\
\hline
\end{tabular}




